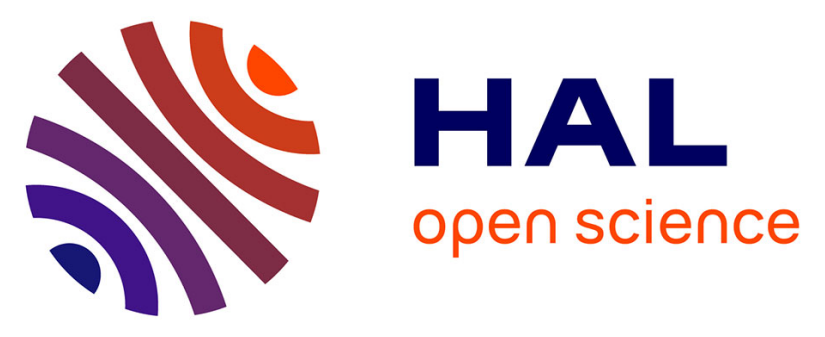

\title{
Time-dependent deformation and failure of granite based on the virtual crack incorporated numerical manifold method
}

Xian-Yang Yu, Tao Xu, Michael Heap, Patrick Baud, Thierry Reuschle, Zhen Heng, Wan-Cheng Zhu, Xing-Wei Wang

\section{To cite this version:}

Xian-Yang Yu, Tao Xu, Michael Heap, Patrick Baud, Thierry Reuschle, et al.. Time-dependent deformation and failure of granite based on the virtual crack incorporated numerical manifold method. Computers and Geotechnics, 2021, 133, pp.104070. 10.1016/j.compgeo.2021.104070 . hal-03179966

\section{HAL Id: hal-03179966 https://hal.science/hal-03179966}

Submitted on 24 Mar 2021

HAL is a multi-disciplinary open access archive for the deposit and dissemination of scientific research documents, whether they are published or not. The documents may come from teaching and research institutions in France or abroad, or from public or private research centers.
L'archive ouverte pluridisciplinaire HAL, est destinée au dépôt et à la diffusion de documents scientifiques de niveau recherche, publiés ou non, émanant des établissements d'enseignement et de recherche français ou étrangers, des laboratoires publics ou privés. 
1 Time-dependent deformation and failure of granite based on the virtual

2 crack incorporated numerical manifold method

3 Xian-yang Yu ${ }^{\mathrm{a}, \mathrm{b}}$, Tao Xu ${ }^{\mathrm{a}, *}$, Michael J. Heap ${ }^{\mathrm{b}}$, Patrick Baud ${ }^{\mathrm{b}}$, Thierry Reuschlé ${ }^{\mathrm{b}}$, Zhen Henga, Wan-

4 cheng $\mathbf{Z h u}^{\mathrm{a}}$, Xing-wei Wang ${ }^{\mathrm{a}}$

$5 \quad{ }^{a}$ Center for Rock Instability and Seismicity Research, Northeastern University, Shenyang 110819, China

$6 \quad$ buniversité de Strasbourg, CNRS, ENGEES, Institut Terre et Environnement de Strasbourg, UMR 7063, 5 rue

7 René Descartes, Strasbourg F-67084, France

$8 \quad *$ Corresponding author: xutao@mail.neu.edu.cn

9 Abstract

10 Micro-cracks are known to greatly affect the mechanical properties of granite and subcritical crack growth (SCG) is 11 considered to be the main mechanism of brittle creep in rocks, including granite. Here, we provide new uniaxial 12 compressive strength and creep experiments for Lanhélin granite, and a new multi-crack numerical model to explain the 13 experimental observations. We first thermally-stressed our granite samples to create thermal micro-cracks. Uniaxial 14 compressive strength experiments were then used to find the uniaxial compression strength of the thermally-cracked granite, 15 a pre-requisite for brittle creep experiments. We introduced a new model that combines SCG theory and the numerical 16 manifold method (NMM) to link the local damage caused by micro-crack propagation and the macroscopic creep 17 deformation observed in the granite samples. We also investigated the influence of virtual micro-crack length, confining 18 pressure, and differential stress on brittle creep behavior. According to our model, we can numerically simulate the entire creep process, from the small deformation caused by micro-cracks to the large displacement characteristic of brittle creep. The fact that the numerical simulations are in good agreement with experimental results shows that the NMM combined with the SCG theory is a suitable method for modeling the creep behavior of rocks.

22 Keywords: Time-dependent deformation; Numerical manifold method; Subcritical crack growth; Multi-crack propagation; Lanhélin granite 


\section{Introduction}

The long-term stability of engineering rock mass structures have been of practical concern for many years[1].

Time-dependent deformation of rock has a significant influence on the stability of rock slopes and underground structures such as mines and tunnels, as well as the long-term strength of the Earth's upper crust[2, 3]. Timedependent deformation under these conditions is known as brittle creep[4], which is the name applied to the slow deformation of solids under loads below their short-term strength [5]. Creep strain and strain rates are very sensitive to differential stress, confining pressure, and temperature. Indeed, even small changes in any of these parameters will produce order of magnitude changes in creep strain rates[6,7]. Many researchers have found that micro-crack propagation in a rock mass is one of main parameters that influences the creep strain rate[8].

The influence of slow crack growth (subcritical crack growth (SCG)) on fracture stress was first examined in detail by Charles[9]. One of the most important mechanisms of subcritical crack growth (known as static fatigue or delayed failure) is stress corrosion[10]. During crack propagation, stress corrosion can explain a certain proportion of the relationship between the stress intensity factor $(\mathrm{K})$ and the crack velocity (V)[11]. SCG theory in rock masses has been also used to explain the growth and development of joints, volcanic eruptions, and underground excavations[12]. The double torsion experimental method was adopted to investigate SCG theory[13, 14]. Nara and co-workers have provided a large number of SCG experiments to better understand the influence of environment on crack velocities in rocks[15]. These authors also found that the physical properties of different rocks also have an effect on SCG[16]. Because creep experiments take a lot of time, numerical simulations, which can give good approximate results in a relatively short time[17], are of great interest. Indeed, many researchers have used numerical simulations to study rock creep and SCG. For example, Desai[18] used a finite-element (FE) program with the implementation of the disturbed-state concept (DSC) creep model to study creep- and rate-dependent behavior of glacial tills to better understand the motion of overlying glaciers. Brantut[19] used a micromechanical model to describe the brittle rock creep, based on the sliding wing-crack model. Konietzky[20] used Fast Lagrangian Analysis of Continua (FLAC) to simulate timedependent crack growth of granite. These authors used the SCG theory to model a virtual crack within an element to describe rock damage. Discontinuous deformation analysis (DDA), which analyzes the forcedisplacement interactions of block systems, was proposed by Shi[21] and has also been used to investigate creep problems[22]. Zheng[23] researched the contact force to improve the algorithm of DDA. $\mathrm{Xu}[24,25]$ proposed 
53 a thermomechanical time-dependent deformation model based on laboratory tests on Beishan granite under

54 constant elevated temperatures and found that this model can accurately describe brittle creep.

The numerical manifold method (NMM) is a new simulation method which provides a unified framework for solving problems dealing with continuous media, discontinuous media, or both[26]. The independent response variables when using NMM, such as displacements, can be continuous or discontinuous throughout the problem domain[27]. The NMM has gained a wide attention and application in rock mechanics and engineering due to

59 its efficient treatment of problems involving continuous and discontinuous deformations in a unified way[28-

60 32]. An[33] introduced a new concept of "weak-discontinuous physical covers" to improve the advantage of 61 the partition of unity of NMM. NMM is suitable to solve crack propagation problems in simulations $(\mathrm{Wu}[34]$, Yang[35] and Zhou[36]). Zheng[37] combined the moving least squares (MLS) interpolation with NMM to analyze the unconfined flow in porous media, which can provide high accuracy and numerical stability. Yang[38] proposed a general mass lumping scheme applicable to higher order elements, which improved the efficiency of NMM to calculate the large deformation of distorted meshes. Using the time step-initial strain method, the creep equation was coupled with the NMM to simulate the time-dependent deformation of rocks[39, 40]. $\mathrm{Wu}[41]$ also used the $\mathrm{NMM}$ to analyze viscoelastic material creep crack problems by incorporating a generalized Kelvin-Voigt model into the NMM.

\section{Constitutive model}

\section{1 Crack Growth Criteria}

Before using the NMM to consider crack problems, the criteria that have an important influence on calculating the crack initiation and propagation angle must be considered. In this paper, two different crack growth criteria are introduced: the maximum circumferential stress criterion (MCSC)[42] and Mohr-Coulomb's shear strength criterion (MCSSC)[43]. For MCSC, the crack propagates in the direction of the maximum circumferential stress. The stress field at the crack tip can be formulated in terms of stress intensity factors (SIFs):

$$
K_{\mathrm{I}} \sin \theta_{0}+K_{\mathrm{II}}\left(-1+3 \cos \theta_{0}\right)=0
$$


where $K_{I}$ and $K_{I I}$ are respectively the stress intensity factors corresponding to mode I and mode II loading, and $\theta_{0}$ is the kinking angle, which corresponds to the crack propagation angle. The direction of maximum circumferential stress is then:

$$
\theta_{0}=2 \arctan \frac{1}{4\left(K_{\mathrm{II}} / K_{\mathrm{I}}\right)}\left\{1 \pm\left[1+8\left(K_{\mathrm{II}} / K_{\mathrm{I}}\right)^{2}\right]^{1 / 2}\right\}
$$

The MCSC can well predict the fracture direction in two mixed modes if there are several cracks in the sample. In nature, however, there are many cracks, joints, and holes in rock masses, and every flaw will influence the local stress field, which can greatly influence the direction of the maximum circumferential stress.

We used the MCSSC to deal with this problem.

In classical engineering science, the SIFs are greatly sensitive to the local stress. Coulomb postulated that the crack initiation depends on the local stress relative to the strength of the material rather than on the SIFs[44]. In this framework, the material strength parameters are the cohesion and the angle of internal friction, as shown in Figure 1. The MCSSC can be used to calculate shear and tensile cracks. As shown in Figure $1, \sigma_{1}$ and $\sigma_{3}$ are the maximum and minimum principle stresses, respectively, $\sigma_{\mathrm{t}}$ is the tensile stress, and $\mathrm{R}$ and $\mathrm{r}$ are expressed as:

90

$\left\{\begin{array}{l}R=c \cos \phi+\frac{\sigma_{1}+\sigma_{3}}{2} \sin \phi \\ \mathrm{r}=\frac{\sigma_{1}+\sigma_{3}}{2}\end{array}\right.$

where $\mathrm{c}$ and $\phi$ are cohesion and the internal friction angle, respectively.
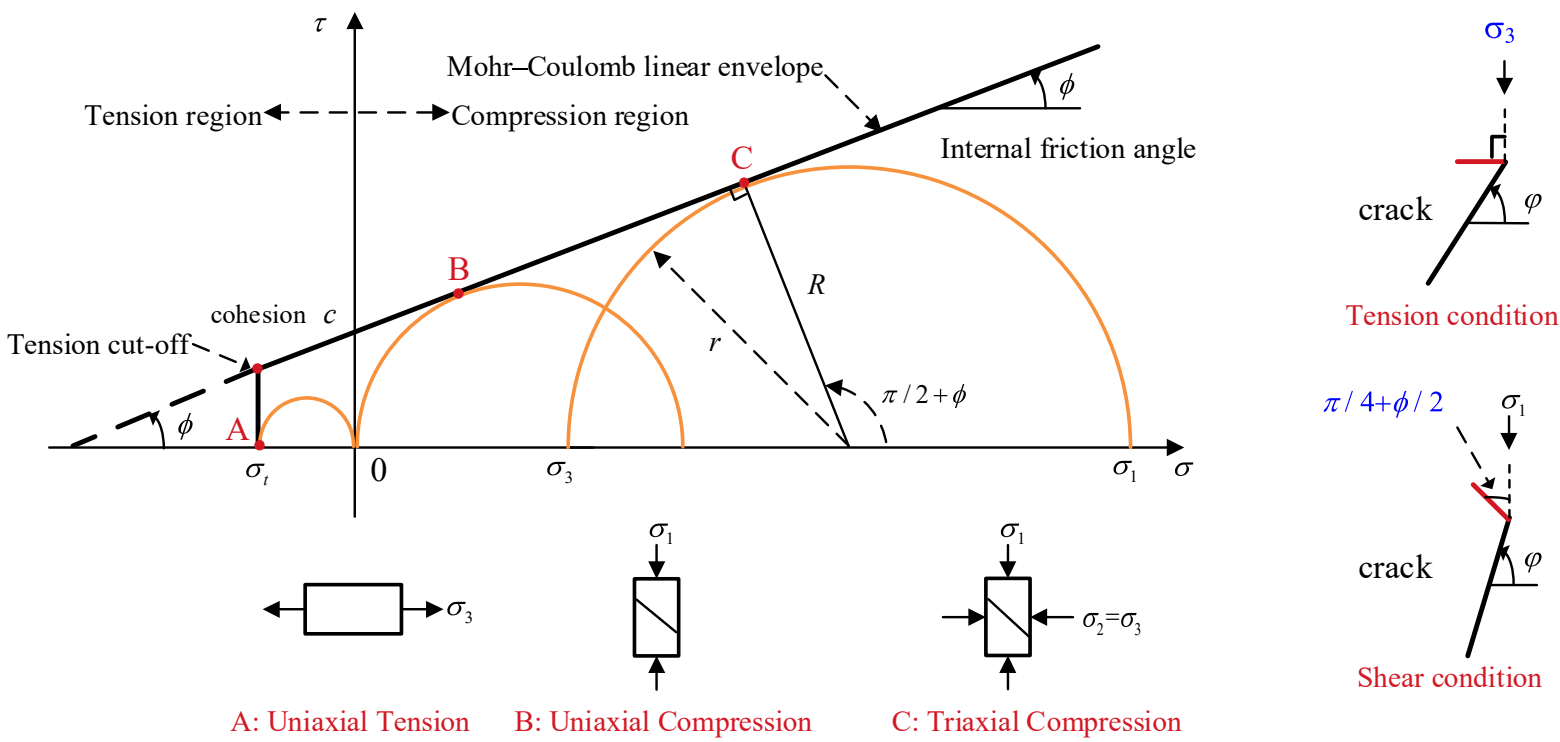

Figure 1 The Mohr-Coulomb criterion for the elements of the numerical model 
95 When the crack satisfies the shear condition:

96

$$
\left\{\begin{array}{c}
R=r \\
\sigma_{3}>-\sigma_{t}
\end{array}\right.
$$

97 the crack initiation angle will be:

$98 \quad \theta=\pi / 4+\varphi / 2$

99 where $\varphi$ is the crack initiation angle.

100 When the crack satisfies the tensile condition:

101

$$
\left\{\begin{array}{c}
R>r \\
\sigma_{3}<-\sigma_{\mathrm{t}}
\end{array}\right.
$$

102 According to $\mathrm{Wu}[43]$, when the condition expressed in Eq. 6 is satisfied, the direction of crack propagation will

103 be perpendicular to the direction of the minimum principal stress, $\sigma_{3}$. On the other hand, the crack initiation 104 angle will be in the direction of the maximum principal stress, $\sigma_{1}$.

\subsection{Subcritical Crack Growth (SCG)}

106 In classical fracture mechanics theory, the crack will not propagate if the SIFs at the crack tip are lower than 107 the fracture toughness Kc. However, some researchers also find that cracks still propagate when the SIFs are 108 lower than Kc, but at a certain lower velocity. This is called subcritical crack growth (SCG) theory[45]. Figure 1092 shows a schematic stress intensity factor $(\mathrm{K})$ against crack velocity $(V)$ curve. Kscc is a critical value, which 110 is a material property. When $\mathrm{K}<\mathrm{Kscc}$, the crack cannot propagate. When $\mathrm{Kscc}<\mathrm{K}<\mathrm{Kc}$, the crack propagates 111 as described by SCG theory (Figure 2). Nara and co-workers performed a lot of SCG experiments[46], which 112 show that, regardless of the environmental conditions, the subcritical crack velocity always increases as a 113 function of increasing stress intensity factor (Figure 2). 


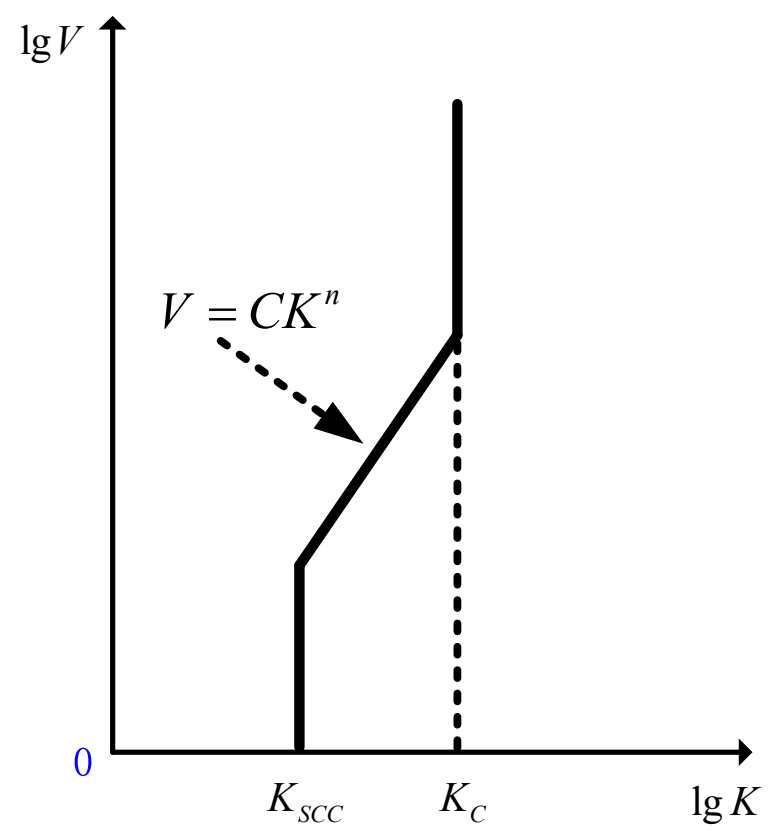

115 Figure 2 Schematic diagram showing a typical stress intensity factor $(\mathrm{K})$ against crack velocity $(V)$ curve 116 The crack velocity is governed by Charles' equation:

$$
\left\{\begin{array}{l}
V=C K^{\mathrm{n}} \\
K=\sqrt{K_{\mathrm{I}}^{2}+K_{\mathrm{II}}^{2}}
\end{array}\right.
$$

where $\mathrm{C}$ is a material constant, $\mathrm{K}$ is the total $\mathrm{SIF}$, which consists of $\mathrm{K}_{\mathrm{I}}$ and $\mathrm{K}_{\mathrm{II}}, \mathrm{n}$ is the stress corrosion index, $V$

119 is the crack velocity, and $\triangle \mathrm{t}$ is the time step. The crack length $\mathrm{L}^{\prime}$ at every step is $V \triangle \mathrm{t}$.

120 The SIFs $\mathrm{K}_{\mathrm{I}}$ and $\mathrm{K}_{\mathrm{II}}$ are calculated as:

$$
\left\{\begin{array}{l}
K_{\mathrm{I}}=\sigma_{\mathrm{n}} \sqrt{\pi a} \\
K_{\mathrm{II}}=\tau_{\mathrm{n}} \sqrt{\pi a}
\end{array}\right.
$$

When the crack is under the tension-shear condition, where $\sigma_{\mathrm{n}}$ and $\tau_{\mathrm{n}}$ are the maximum tensile normal stress and maximum shear stress, respectively, $\mathrm{a}$ is the half crack length, and $\sigma_{\mathrm{n}}$ and $\tau_{\mathrm{n}}$ are expressed as:

$$
\left\{\begin{array}{l}
\sigma_{\mathrm{n}}=\frac{1}{2}\left[\left(\sigma_{1}+\sigma_{3}\right)+\left(\sigma_{1}-\sigma_{3}\right) \cos 2 \varphi\right] \\
\tau_{\mathrm{n}}=\frac{1}{2}\left(\sigma_{1}-\sigma_{3}\right) \sin 2 \varphi
\end{array}\right.
$$

125 where $\varphi$ is the original angle of the crack.

126 When the crack is under the compress-shear condition, where $\tau_{\text {eff }}$ is effective shear stress and $\mu$ is the 127 friction coefficient, $\tau_{\text {eff }}$ and $\mathrm{K}_{\mathrm{II}}$ are expressed as: 


$$
\begin{aligned}
& \tau_{\text {eff }}=\left|\tau_{\mathrm{n}}\right|-\mu\left|\sigma_{\mathrm{n}}\right| \\
& K_{\mathrm{II}}=\left|\tau_{\text {eff }}\right| \sqrt{\pi a}
\end{aligned}
$$

\section{Fundamentals of NMM}

\subsection{Dual cover system of NMM}

The NMM consists two of important components: the cover system and the block dynamics. The cover system is a dual cover system, which includes a mathematical cover (MC) of three-node triangle elements and a physical cover (PC) that includes the boundary, the material interface, and the crack. The block dynamics is used to solve the mechanical behavior of block systems under loading and block contact. The NMM program runs on the MATLAB $^{\circledR}$ platform.

Figure 3 shows the dual cover system containing MC and PC. We can see in Figure 3(a) that there are three MCs that are coloured orange, green, and red, that every MC is a hexagon consisting of six triangles, and that the node of every triangle is at the centre of the MC. If there a crack that cuts through the triangle $\mathrm{ABC}$ (such as $\mathrm{D}_{1}-\mathrm{D}_{5}$ in Figure 3), the three MCs are changed. It is shown in Figures 3(b) and (d) that the crack does not cut the $\mathrm{MC}(\mathrm{A}$ and $\mathrm{C})$ into two parts. Instead, the hexagon and a part of the crack consist of a $\mathrm{PC}$, which are $\mathrm{A}_{1}-\mathrm{A}_{2-}$ $\mathrm{A}_{3}-\mathrm{A}_{4}-\mathrm{D}_{3}-\mathrm{D}_{4}-\mathrm{D}_{5}-\mathrm{D}_{4}{ }^{\prime}-\mathrm{D}_{3}{ }^{\prime}-\mathrm{A}_{5}-\mathrm{A}_{6}-\mathrm{A}_{1}$ and $\mathrm{C}_{1}-\mathrm{C}_{2}-\mathrm{C}_{3}-\mathrm{C}_{4}-\mathrm{C}_{5}-\mathrm{D}_{2}-\mathrm{D}_{3}-\mathrm{D}_{4}-\mathrm{D}_{5}-\mathrm{D}_{4}{ }^{\prime}-\mathrm{D}_{3}{ }^{\prime}-\mathrm{D}_{2}{ }^{\prime}-\mathrm{C}_{6}-\mathrm{C}_{1}$, respectively. In Figure 3(c), the crack cuts the $\mathrm{MC}(\mathrm{B})$ into two parts $\left(\mathrm{B}\right.$ and $\left.\mathrm{B}^{\prime}\right)$ and so there are two PCs, which are $\mathrm{B}_{1}-\mathrm{B}_{2}-\mathrm{D}_{4}{ }^{\prime}-\mathrm{D}_{3}{ }^{\prime}-$ $\mathrm{D}_{2}{ }^{\prime}-\mathrm{D}_{1}{ }^{\prime}-\mathrm{B}_{5}-\mathrm{B}_{6}-\mathrm{B}_{1}$ and $\mathrm{D}_{4}-\mathrm{B}_{3}-\mathrm{B}_{4}-\mathrm{D}_{1}-\mathrm{D}_{2}-\mathrm{D}_{3}-\mathrm{D}_{4}$, respectively.

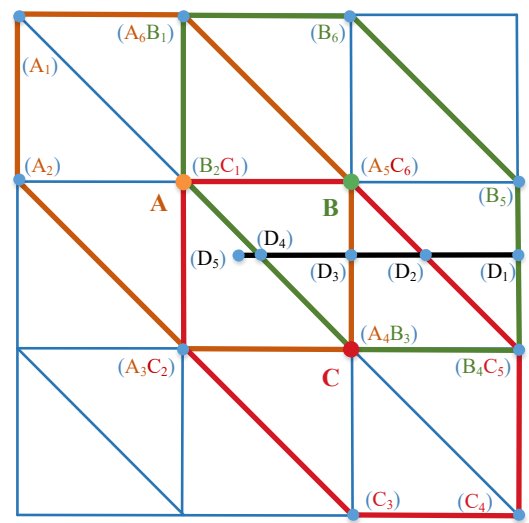



(b)

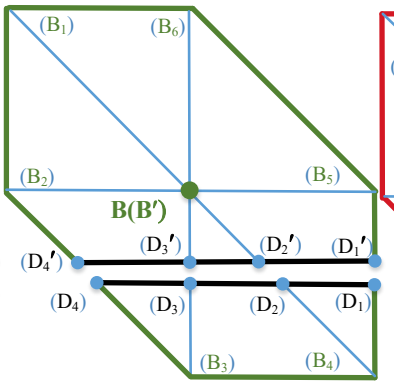

(c)

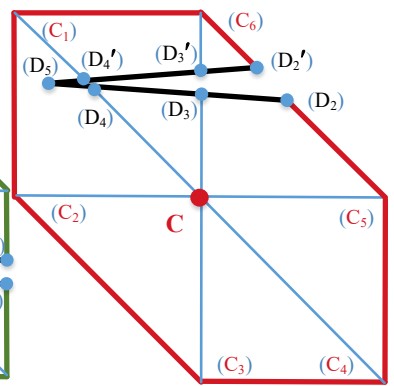

(d)

Figure 3 Dual cover system and crack cutting theory of NMM

\subsection{Contact theory of NMM}


The loop contact is very important in NMM to identify the physical cover (PC), which includes the boundary, the material interface, and the crack. The loop consists of closed segments connected from the first to the last. In Figure 4, the black line is the boundary of model and the blue line is the crack. In NMM, the loop rotates counter-clockwise and a complete loop indicates a whole body (i.e. the crack boundary zone is empty in NMM), which is the same as making a hole in the model (Figure 4).

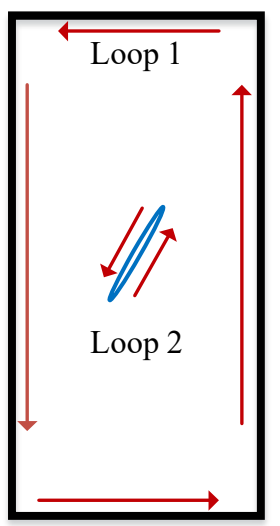

(a)

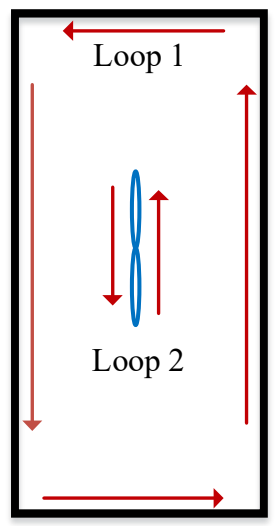

(d)

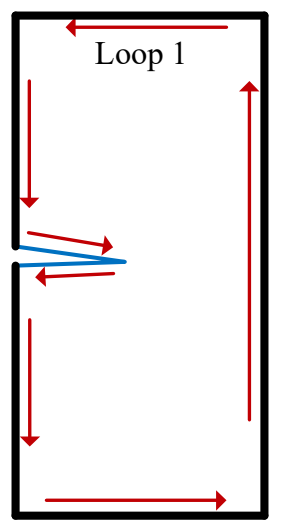

(b)

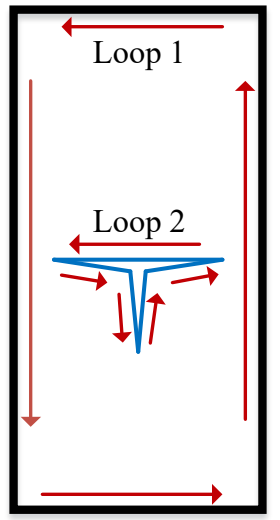

(e)
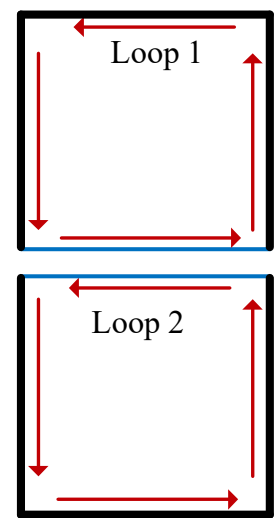

(c)

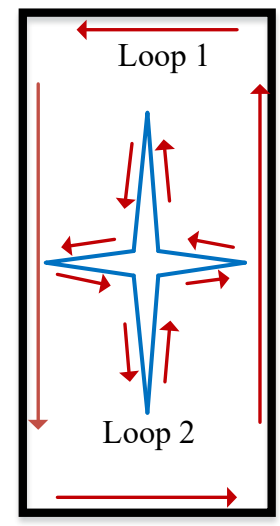

(f)

Figure 4 Single-and multi-crack loop conditions of NMM

Figures 4(a), 4(b), and 4(c) are single crack loop models, which show different possible locations of cracks within the model. Figure 4(a) shows the condition when there is a crack inside the model. In this case, the crack itself can generate an independent loop. Indeed, the two loops in Figure 4(a) have no intersection point. Figure 4(b) shows the condition when there is crack tip on the boundary of model. In this scenario, the crack will combine with the boundary to generate a single whole loop (Figure 4(b)). If the crack cuts the model into two parts, which is shown in Figure 4(c), the program will generate two independent loops. However, the sample will have to contain a lot of cracks to simulate a natural rock and, as the population of micro-cracks grow, they 
can coalescence and transform into a macro-crack. This transformation forms a large crack zone. It is therefore

162 important to study the coalescence of cracks. There are three crack coalescence types during crack propagation,

163 which are crack tip to crack tip ("tip and tip" crack model, TT model), crack tip to crack boundary ("tip and

164 boundary" crack model, TB model) and crack boundary to crack boundary ("boundary and boundary" crack model, BB model) respectively. Figure 4(d) shows the TT model. In this case, the two cracks have a common crack tip and so they can generate a new larger crack with an independent loop, and the crack tip of the intersection will disappear (Figure 4(d)). If a crack propagates to another crack boundary, there will be a TB model, which is shown in Figure 4(e). In the TB model, the two cracks can generate a new crack with three crack tips. If one crack propagates across the other crack boundary, there will be a BB model. In the BB model, the two cracks can generate a new crack with four crack tips (Figure 4(f)).

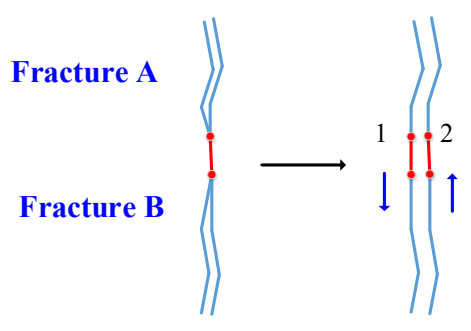

TT model

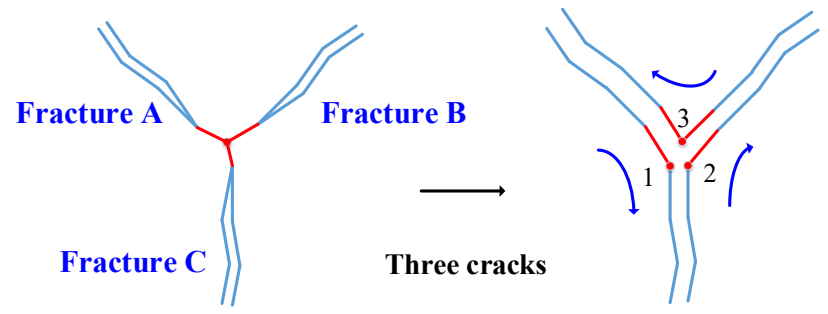

TB model

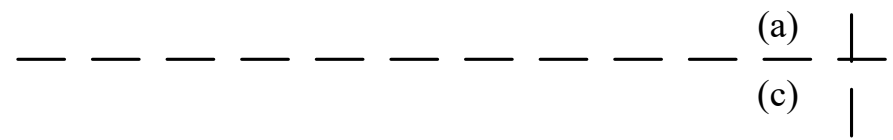

(b)



TB model

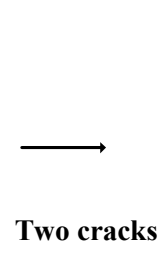

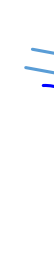



171

\section{Figure 5 Different types of loop intersection during crack propagation in NMM}

Figure 5 shows the different types of loop intersection during crack propagation. The different loop intersection types correspond to the different number of intersection points: the TT model has two intersection points (Figure 5(a)), the TB model has three intersection points (Figure 5(b) and (c)), and the BB model has 
176 four intersection points (Figure 5(d)). The TB model has two different types, the first type is when three crack 177 tips propagate to the same intersection point (Figure 5(b)) and the second type is when a crack tip propagates to 178 the boundary of another crack (Figure 5(c)). When three crack tips are propagating, the order of the crack 179 propagation is that the first two cracks propagate according to the TT model and the third crack propagates according to the TB model. As a result, the three crack tips propagation type is still considered as a TB model. For a complete single loop connected from the first and last loop points, the loop segments at the intersection crack loop should be empty.

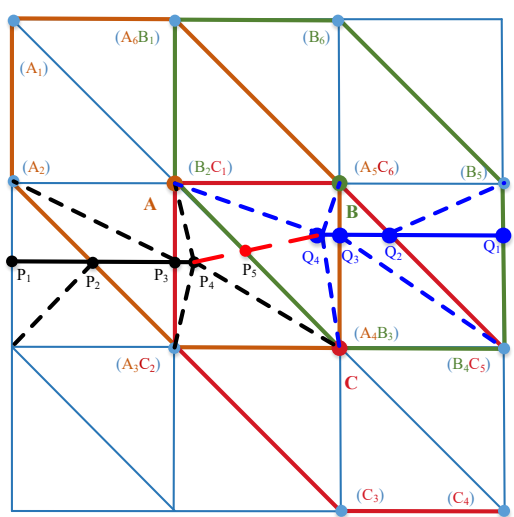

(a)

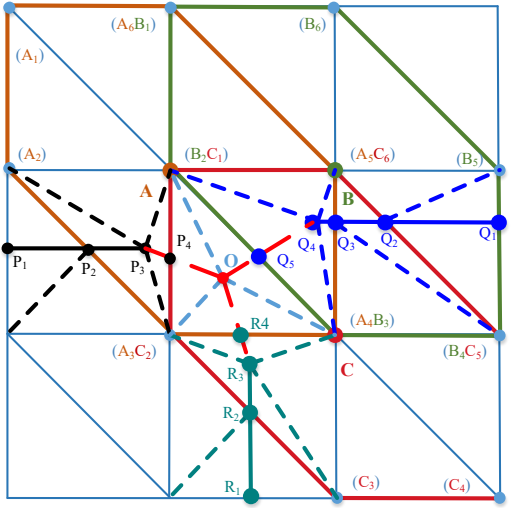

(b)

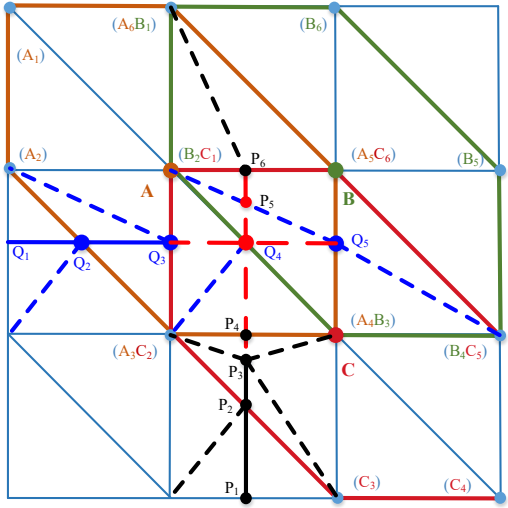

(c)

Figure 6 Form of element cutting during multi-crack intersection in NMM (Fig. 6 shows the propagating and cutting progress during multi-crack intersection in NMM. In Fig. 6(a), the black crack tip is $\mathrm{P}_{4}$ and, when black crack propagates to the blue crack tip $\mathrm{Q}_{4}$, this is TT model. Following crack propagation, crack tips $\mathrm{P}_{4}$ and $\mathrm{Q}_{4}$ disappear. The dotted line is the element segmentation progress. Fig. 6(b) is the TB model. There are three cracks in the TB model: cracks $\mathrm{P}_{1} \mathrm{P}_{3}, \mathrm{R}_{1} \mathrm{R}_{4}$, and $\mathrm{Q}_{1} \mathrm{Q}_{4}$. These three cracks propagate to the same point $\mathrm{O}$. Cracks $\mathrm{P}_{1} \mathrm{P}_{3}$ and $\mathrm{Q}_{1} \mathrm{Q}_{4}$ first propagate according to the $\mathrm{TT}$ model and, later, the crack $\mathrm{R}_{1} \mathrm{R}_{4}$ propagates. After the three cracks propagate, the three crack tips $\mathrm{P}_{4}, \mathrm{R}_{4}$, and $\mathrm{Q}_{4}$ disappear. Fig. 6(c) is the BB model. In this model, the crack $\mathrm{P}_{1} \mathrm{P}_{4}$ propagates across the crack $\mathrm{Q}_{1} \mathrm{Q}_{5}$, and the crack tips $\mathrm{P}_{6}$ and $\mathrm{Q}_{5}$ do not disappear.)

Figure 6 shows the form of element cutting by multi-crack intersection. Figure 6(a) shows the intersection of two crack tips, which is a TT model. We assume that crack P propagates, and that crack Q does not propagate. The new crack is $\mathrm{P}_{4} \mathrm{Q}_{4}$. After the crack propagation event, the program generates four new elements, which are $\mathrm{AP}_{4} \mathrm{P}_{5}, \mathrm{CP}_{5} \mathrm{P}_{4}, \mathrm{AP}_{5} \mathrm{Q}_{4}$, and $\mathrm{CQ}_{4} \mathrm{P}_{5}$, respectively. The two cracks then connect to form a new crack and the intersection point of the new crack is $\mathrm{Q}_{4}$. In order to have the new loop, the program rearranges the four new 
198 elements and the former elements cut by cracks P and Q. The program deals with multi crack intersection in the 199 same way. Figure 6(b) shows the three crack tips intersection: the three cracks propagate to the same point O, 200 which is the intersection point. Figure 6(c) shows the two cracks boundary intersection, and the intersection 201 point is $\mathrm{Q}_{4}$.

202 Each element on the loop is likely to come into contact with other elements on the loop. As a result, both the 203 contact search and judgment are based on elements that are located on the loop. These elements located on the 204 loop are the contact elements. NMM uses the Mohr-Coulomb criterion and maximum tensile strength criterion 205 to handle the possibility of embedding, pulling, and friction during contact. The laws of contact theory of NMM 206 are as follows:

207 1. Penetration does not occur during contact.

2082 2. The pulling stress is less than the tensile strength during contact.

209 3. The Mohr-Coulomb criterion is satisfied during contact.

210 These three laws are executed by applying or releasing contact springs (open-close iteration) to modify the 211 contact status and realize the no tension force and no penetration between two contacts[32, 47, 48].

212 The rectangular contact search method (RCSM) is used to determine whether there is a contact between two 213 potential CE. Figure 7 shows a diagram of the RCSM, where $\mathrm{d}_{0}$ is the one step maximum displacement (safe 214 displacement). Before every time step of the numerical simulation, the program makes contact judgements and 215 calculates the contact condition of every element in the model. There are two contact conditions. If distance 216 between two contact elements is larger than $d_{0}$, these two elements are non-contact elements (Figure 7(a)). 217 However, if distance between two contact elements is smaller than $\mathrm{d}_{0}$, these two elements are contact elements 218 (Figure 7 (b)). 


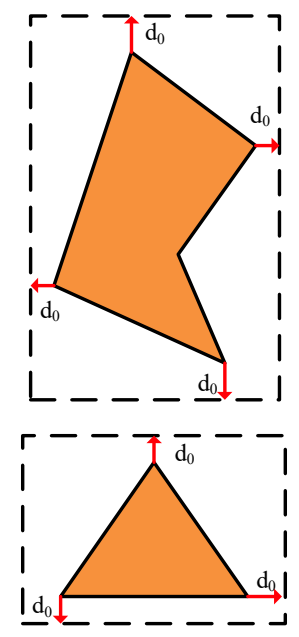

(a)

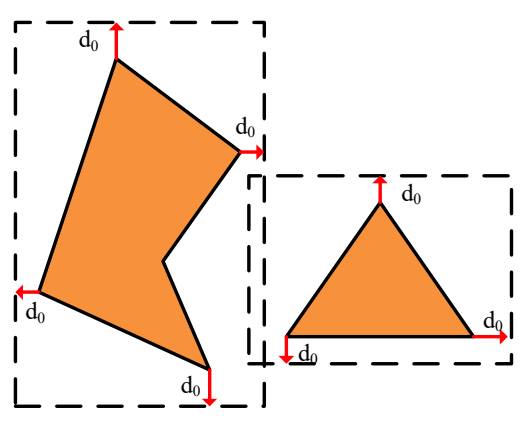

(b)

Figure 7 Diagram of rectangular contact search method of NMM: (a) non-contact element; (b) contact

element

In NMM, there are three contact conditions, as shown in Figure 8: (a) angle to angle, (b) angle to edge, and 223 (c) edge to edge. " $\mathrm{A}$ " and " $\mathrm{B}$ " are two elements. Both angle to angle and edge to edge contacts can be converted 224 into angle to edge contacts. Therefore, it is the distance between the angle in one loop and edge of other loops that influences the contacts judgment in the NMM. Contact distance can be obtained by calculating the distance 226 from angle to edge.

227 When we find the angle and edge of two contact elements, the program will calculate the distance between 228 the angle and the edge. Figures 8(d) and (e) show examples before and after the penetration of two elements, 229 respectively. $\mathrm{P}_{1}$ is the angle before moving, $\mathrm{P}_{4}$ is the angle after moving, and $\mathrm{P}_{2} \mathrm{P}_{3}$ is the penetration edge. The 230 equation for judging penetration is:

$$
\Delta=\left|\begin{array}{ccc}
1 & x_{1}+u_{1} & y_{1}+v_{1} \\
1 & x_{2}+u_{2} & y_{2}+v_{2} \\
1 & x_{3}+u_{3} & y_{3}+v_{3}
\end{array}\right|
$$

232 where $\left(\mathrm{x}_{\mathrm{i}}, \mathrm{y}_{\mathrm{j}}\right)$ and $\left(u_{\mathrm{i}}, v_{\mathrm{j}}\right)$ are coordinate and displacement of $\mathrm{P}_{\mathrm{i}}(\mathrm{i}=1,2,3)$.

233 If $\triangle<0$, the two elements have penetrated, and the program moves the penetration angle back to the outside 234 of the element along the minimum distance. 


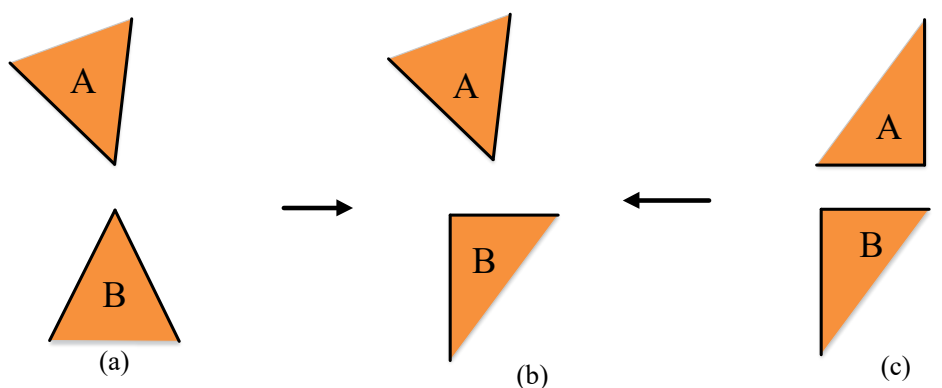

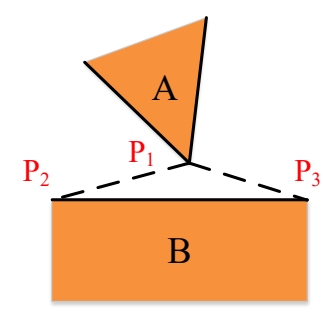

(d)

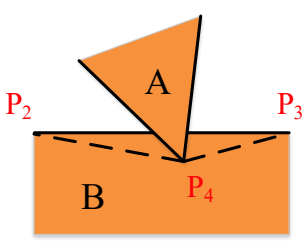

(e)

Figure 8 Three contact conditions and open-close iteration penetration judgement of NMM: (a) angle to angle, (b) angle to edge, (c) edge to edge, (d) before penetration of two elements, (d) after penetration of two elements

\subsection{Crack initiation and coalescence of NMM}

240 Crack initiation and coalescence are a prerequisite for the macroscopic failure of rock. This is true for samples deformed at a constant strain or loading rate and those deformed under a constant stress (i.e. time-dependent brittle creep). During deformation, micro-cracks initiate and coalesce to form a macro-crack zone. It is therefore important to study the connection between micro-crack initiation, propagation, coalescence, and time-dependent 244 deformation.

Compared to XFEM, GFEM, and DEM, NMM is the most advanced to simulate crack initiation, propagation, and coalescence. The dual cover system and the loop concept in NMM allow for crack identification and crack propagation simulation without incorporating additional unknowns to the related nodes through enrichment functions.

Figure 3 introduces the dual cover system and crack cutting theory of NMM, which are the basic theories to 250 realize crack initiation. There is a difference between crack initiation and propagation in the model. When cracks 251 propagate, the crack tip can be located on either the boundary, node, or in the element, and there is no limit to 252 the length of the crack propagation at each step. When cracks initiate, the crack has to traverse the boundary of 253 three MCs at the same time where it is located. Figure 9 shows the crack initiation theory of NMM. In Figure 
254 9(a), a crack " $\mathrm{D}_{1} \mathrm{D}_{2}$ " initiates in the triangle $\mathrm{ABC}$, which is in contact with three $\mathrm{MCs}$ that are coloured orange, 255 green, and red. The locations of crack " $\mathrm{D}_{1} \mathrm{D}_{2}$ " in every MC are shown in Figures 9(b)-(d). In Figures 9(c) and 256 (d), one of the crack tips is located on the boundary of $M C$, the crack " $\mathrm{D}_{1} \mathrm{D}_{2}$ " can form in these two MCs. However, in Figure 9(b), both crack tips are located in the MC and so the crack " $\mathrm{D}_{1} \mathrm{D}_{2}$ " cannot generate in this MC. In order to make the crack " $\mathrm{D}_{1} \mathrm{D}_{2}$ " generate in this $\mathrm{MC}$, we have to extend one of the crack tips to the boundary of MC and make sure the extended length is smaller than the other crack tip. For example, in Figure 9(e), the two crack tips $D_{1}$ and $D_{2}$ extend to $D_{4}$ and $D_{3}$, respectively. $D_{2} D_{3}$ is smaller than $D_{1} D_{4}$ and so the final initiated crack is $\mathrm{D}_{1} \mathrm{D}_{2} \mathrm{D}_{3}$. When the crack initiates, it will transform into a real crack, cut the element, and propagate according to the MCSSC theory.

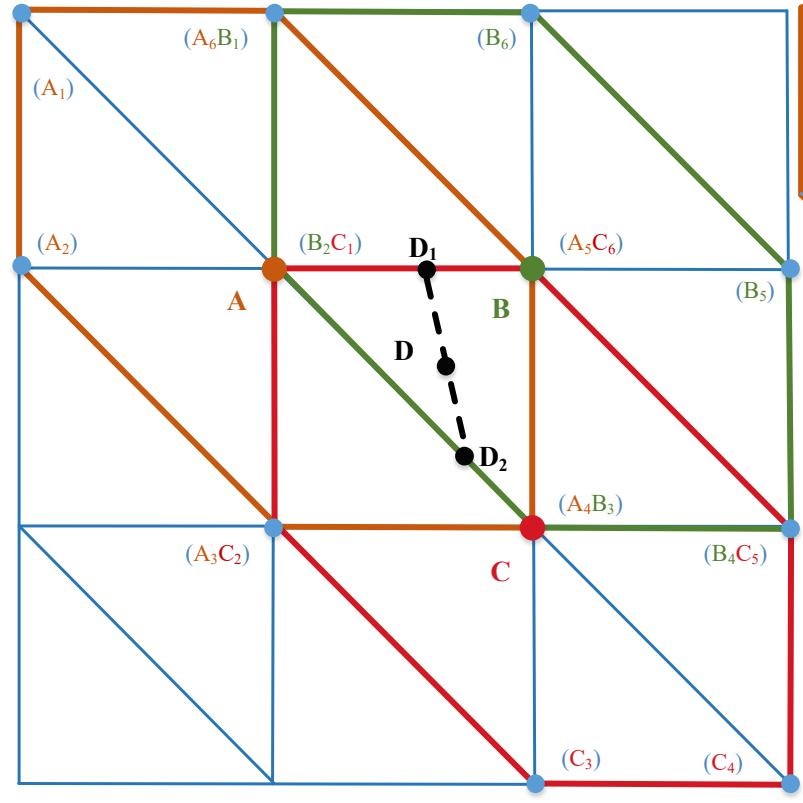

(a)

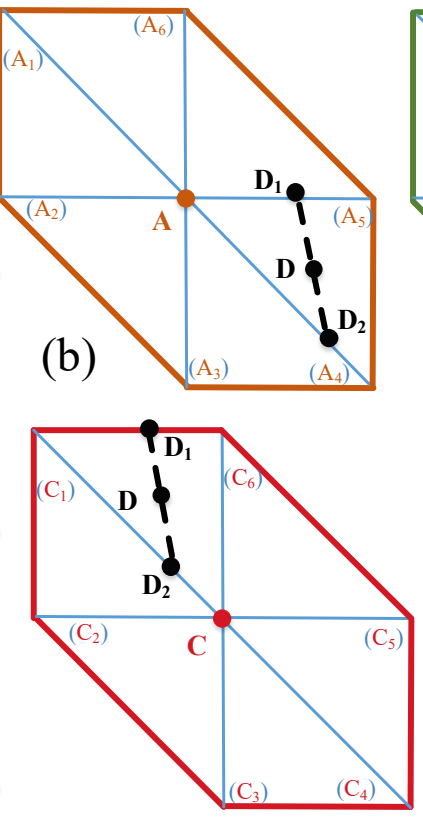

(d)
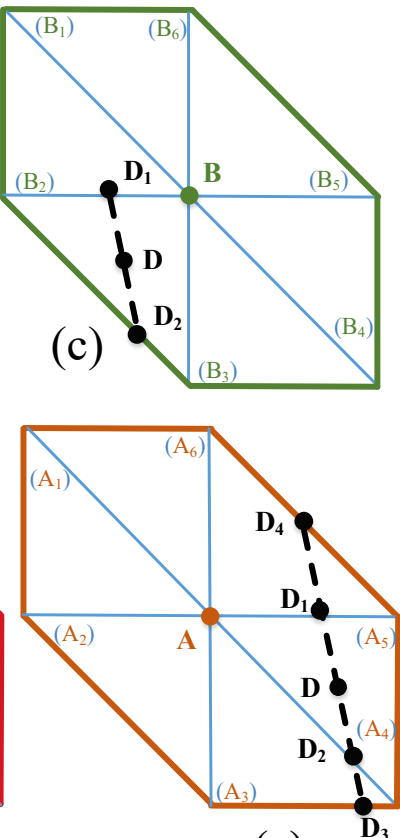

(e)

Figure 9 Crack initiation theory of NMM (Fig. 9 shows the crack initiation and element cutting progress. If

crack $D_{1} D_{2}$ initiates at triangle element $A B C$, the crack center $D$ is also the center of the triangle element. Every triangle element in NMM has three nodes, and every node is the center of a hexagon physical cover. Figs. 9(b), (c), and (d) are three hexagon physical covers. In NMM theory, if one crack wants to initiate successfully, the crack tip has to propagate to the boundary of three hexagons at the same time. In Figs. 9(c) and (d), the crack tip $\mathrm{D}_{2}$ is at the boundary of hexagon $\mathrm{B}$, and the crack tip $\mathrm{D}_{1}$ is at the boundary of hexagon C. In Fig. $9(\mathrm{~b})$, these two crack tips are inside hexagon A. Therefore, the crack tip propagates in two directions, yielding the shortest new crack $\mathrm{D}_{1} \mathrm{D}_{3}$ in Fig. $9(\mathrm{e})$.) 


\subsection{Sample preparation}

274 The material used in this research is Lanhélin granite, which is a coarse-grained, blue-grey granodiorite from 275 Brittany, France. It has an average crystal size of $2 \mathrm{~mm}[49,50]$. Lanhélin granite has important research value 276 in studies of rock deformation and fracture[49-54]. We prepared nine cylindrical rock samples that were $20 \mathrm{~mm}$ 277 in diameter and nominally $40 \mathrm{~mm}$ in length. We then thermally-stressed the nine rock samples in a furnace to a maximum temperature of $600{ }^{\circ} \mathrm{C}$ so that our samples contained thermal micro-cracks. The samples were thermally-stressed in an electric box furnace at room pressure. The furnace was programmed to heat at $1{ }^{\circ} \mathrm{C} / \mathrm{min}$ to a target temperature of $600{ }^{\circ} \mathrm{C}$. The samples then held at the target temperature for two hours before being cooled at $1{ }^{\circ} \mathrm{C} / \mathrm{min}$ back to room temperature. Figure 10 shows the thermal-stressing procedure. The prepared samples were then separated into two groups. The first group is the uniaxial compressive strength group, which has five samples (U-1, U-2, U-3, U-4, and U-5). The second group is the creep deformation group, which has 284 four samples (C-1, C-2, C-3, and C-4).

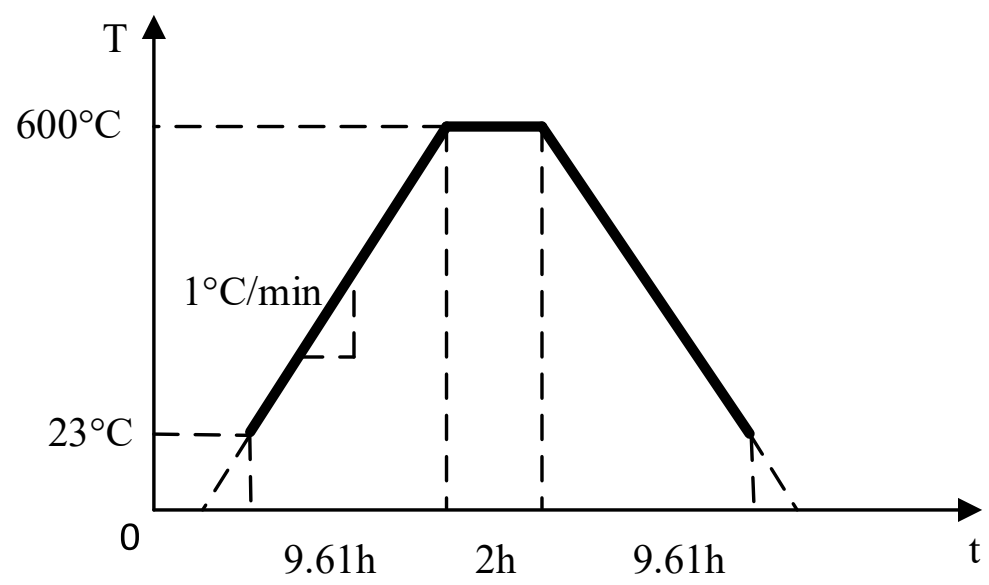

Figure 10 Heating curve of Lanhélin granite samples

Following thermal-stressing, we determined the connected porosities of the nine samples. Connected porosity was determined using the bulk sample volume (measured using digital callipers) and the connected (skeletal) volume measured by an AccuPyc II 1340 helium pycnometer. Following thermal-stressing to $600{ }^{\circ} \mathrm{C}$, the connected porosity of the thermally-stressed samples of Lanhélin granite was about $2 \%$, in agreement with previously published porosity data for thermally-stressed granites[55]. 
Uniaxial compressive strength (UCS) tests and uniaxial creep experiments were performed on dry samples

293 of thermally-stressed Lanhélin granite under ambient laboratory conditions (pressure and temperature) using a 294 uniaxial load frame (Figure 11). Axial displacement and axial load were measured by a linear variable 295 differential transducer (LVDT) and a load cell, respectively. Axial displacement and axial load were converted 296 to axial strain and axial stress using the sample dimensions. During the UCS tests, we also recorded the output 297 of acoustic emission (AE) energy using a USB AE Node (from Physical Acoustics). The threshold for an AE 298 hit was set at $30 \mathrm{~dB}$ in the accompanying program, AEwin. The UCS tests were performed at a constant strain 299 rate of $1 \times 10^{-5} \mathrm{~s}^{-1}$ until macroscopic sample failure. For the creep tests, the samples were first loaded at a constant strain rate of $1 \times 10^{-5} \mathrm{~s}^{-1}$ to a pre-ascribed axial stress (a high percentage of the short-term failure stress determined from the UCS tests). The samples were then left to deform under a constant stress until macroscopic sample failure.

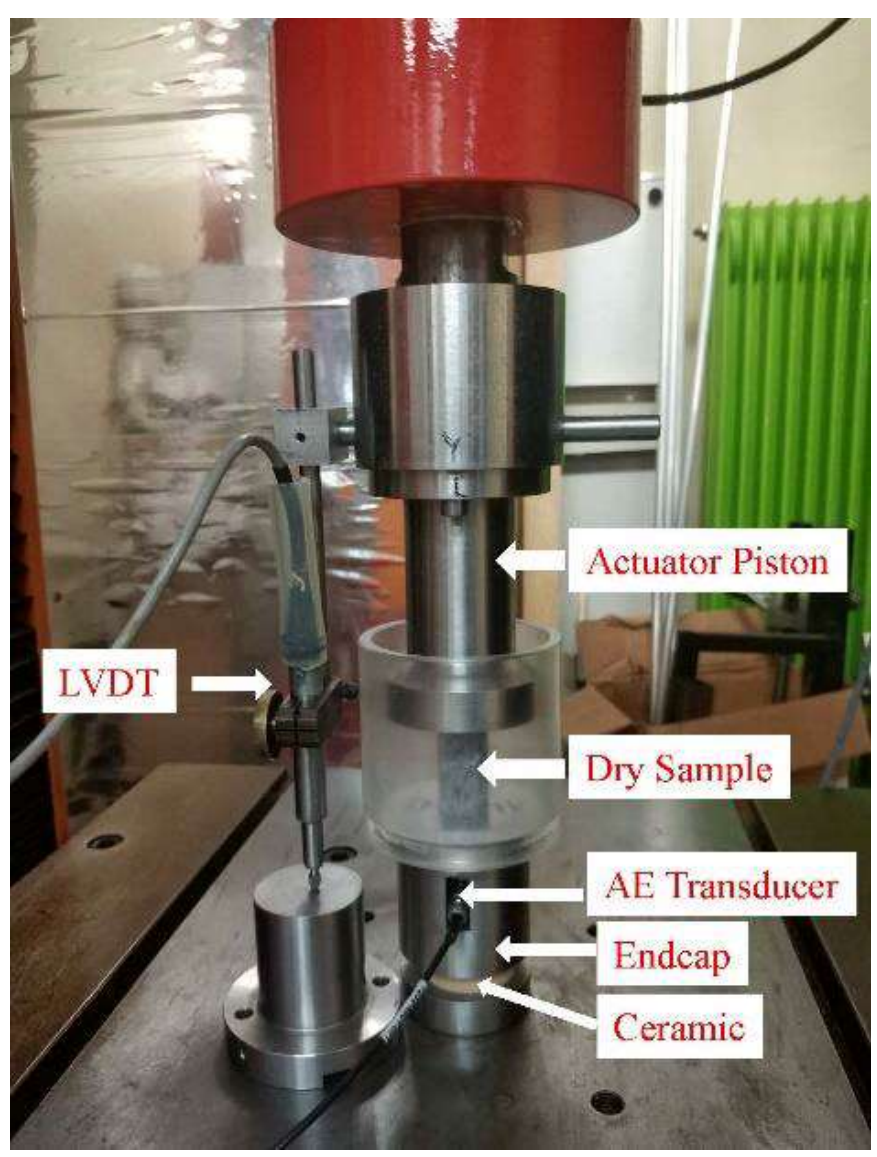

Figure 11 Uniaxial compression apparatus used for the uniaxial compression strength tests and creep experiments presented in this study 
The stress-strain curves for the five UCS tests performed on samples of thermally-stressed Lanhélin granite are shown in Figure 12. These stress-strain curves are typical for crystalline rock deforming under uniaxial compression[56, 57]. The UCS values of the five samples are 123.0, 139.2, 127.6, 120.6, and 139.9 MPa, respectively, and the mean UCS is $130 \mathrm{MPa}\left(\sigma_{\mathrm{p}}\right)$. The mean UCS was used to determine the constant stresses used in the uniaxial creep experiments. We can also calculate the Young's modulus (the slope of the stressstrain curve in the elastic region), which are $26.2,24.7,25.5,26.9$, and $16.4 \mathrm{GPa}$ for the five samples, respectively. The mean Young's modulus is $23.9 \mathrm{GPa}$.

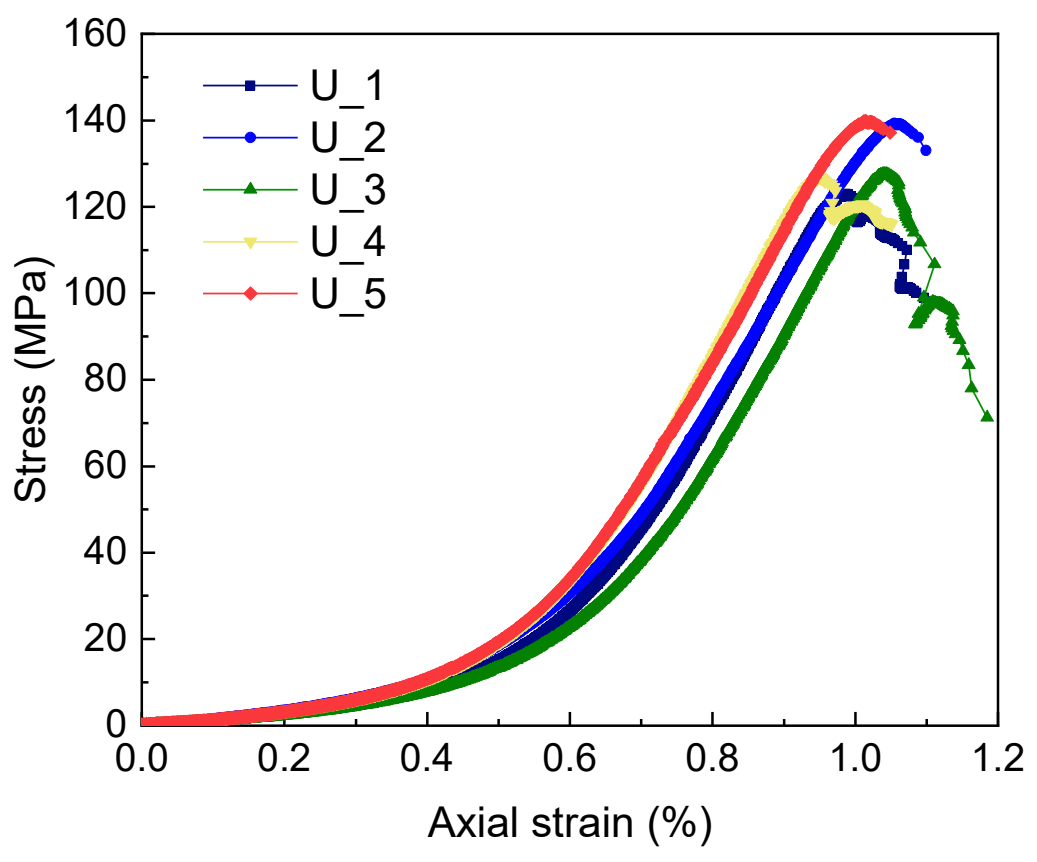

Figure 12 Stress-strain curves for the five uniaxial compressive strength (UCS) tests performed on samples of thermally-stressed Lanhélin granite

In Figure 13 we show the stress-strain curve for sample U-2 alongside the output of AE energy (the area under the received waveform, in arbitrary units). Figure 13 shows that the AE activity increases during the approach to macroscopic sample failure, and that the AE activity was greatest at the point of failure (marked by the stress drop in the mechanical data). 


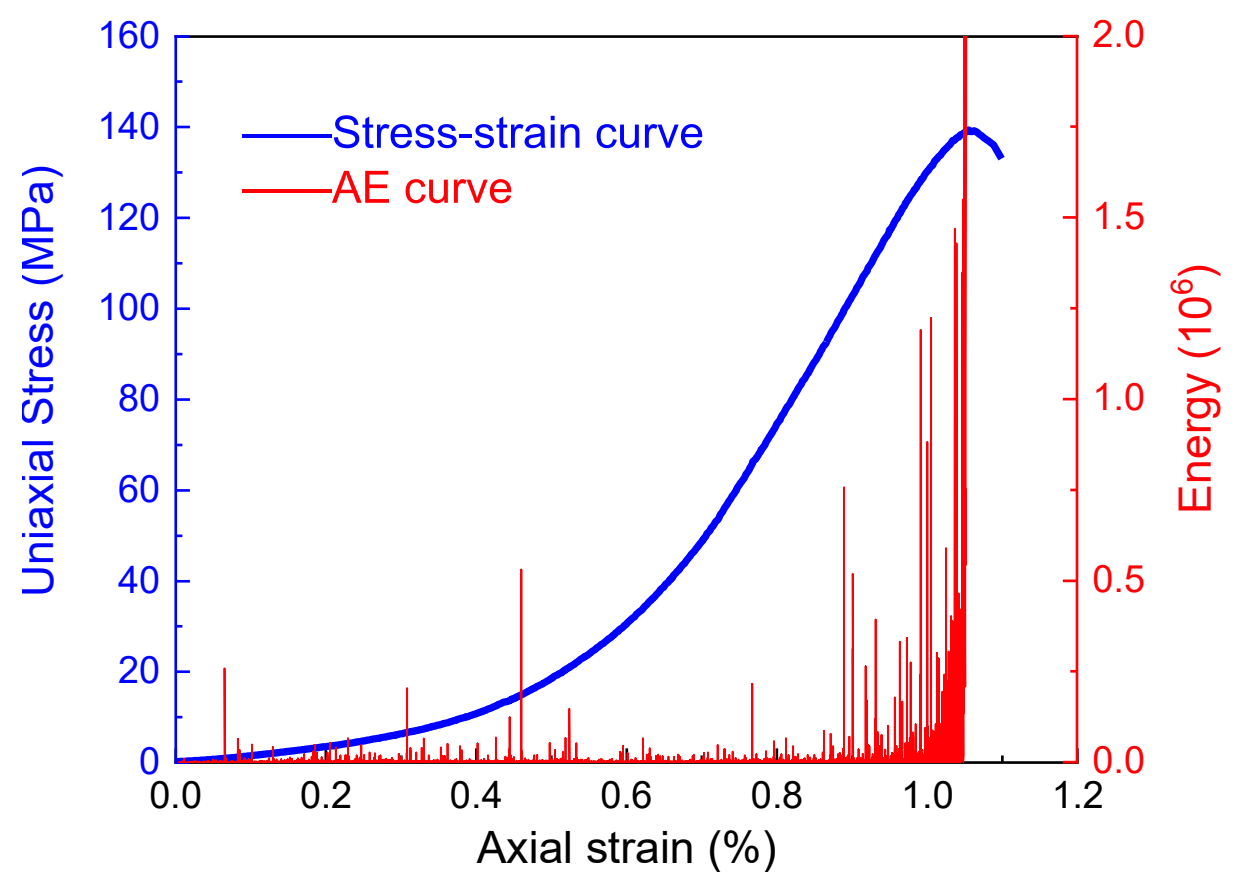

Figure 13 Stress-strain curve for a uniaxial compressive strength (UCS) test performed on a sample of

thermally-stressed Lanhélin granite (sample U-2) alongside the output of acoustic emission (AE) energy

\subsection{Uniaxial creep experiments}

326 Conventional creep experiments were performed on thermally-stressed samples of Lanhélin granite at constant uniaxial stresses of $113.75,115.5,117$, and $120.25 \mathrm{MPa}$, corresponding to $87.5,88.8,90$, and $92.5 \%$ of $\sigma_{\mathrm{p}}$, respectively. Table 1 shows a summary of these uniaxial creep tests. The minimum creep strain rates of the four samples were determined to be $1.9 \times 10^{-9}, 7.4 \times 10^{-8}, 4.2 \times 10^{-8}$, and $5.8 \times 10^{-8} \mathrm{~s}^{-1}$, respectively. The

330 time-to-failure of the four samples were $73.79,2.12,2.91$, and $2.36 \mathrm{~h}$, respectively. These data show that, as the 331 constant axial stress was increased, the minimum creep strain rate and the time-to-failure increased and 332 decreased, respectively (Table 1).

333 Table 1 Summary of the conventional uniaxial creep tests performed on thermally-stressed Lanhélin granite

\begin{tabular}{|c|c|c|c|c|}
\hline $\begin{array}{l}\text { Sample } \\
\text { number }\end{array}$ & $\begin{array}{c}\text { Constant } \\
\text { stress/ MPa }\end{array}$ & $\begin{array}{c}\text { Percentage } \\
\text { of } \sigma_{\mathrm{p}} / \%\end{array}$ & $\begin{array}{c}\text { Minimum Creep Strain } \\
\text { Rate } / \mathrm{s}^{-1}\end{array}$ & Time to failure $/ \mathrm{h}$ \\
\hline $\mathrm{C}-1$ & 113.75 & 87.5 & $1.9 \times 10^{-9}$ & 73.79 \\
\hline $\mathrm{C}-2$ & 115.5 & 88.8 & $7.4 \times 10^{-8}$ & 2.12 \\
\hline $\mathrm{C}-3$ & 117 & 90 & $4.2 \times 10^{-8}$ & 2.91 \\
\hline $\mathrm{C}-4$ & 120.25 & 92.5 & $5.8 \times 10^{-8}$ & 2.36 \\
\hline
\end{tabular}


The four uniaxial creep (i.e. strain as a function of time) curves (for Lanhélin granite performed at constant stresses corresponding to $87.5,88.8,90$, and $92.5 \%$ of $\sigma_{\mathrm{p}}$ ) are shown in Figure 14. The strain rate as a function of time for these four experiments is shown in Figure 15. These curves all exhibit the decelerating followed by accelerating creep behavior observed in previous laboratory creep experiments[6].

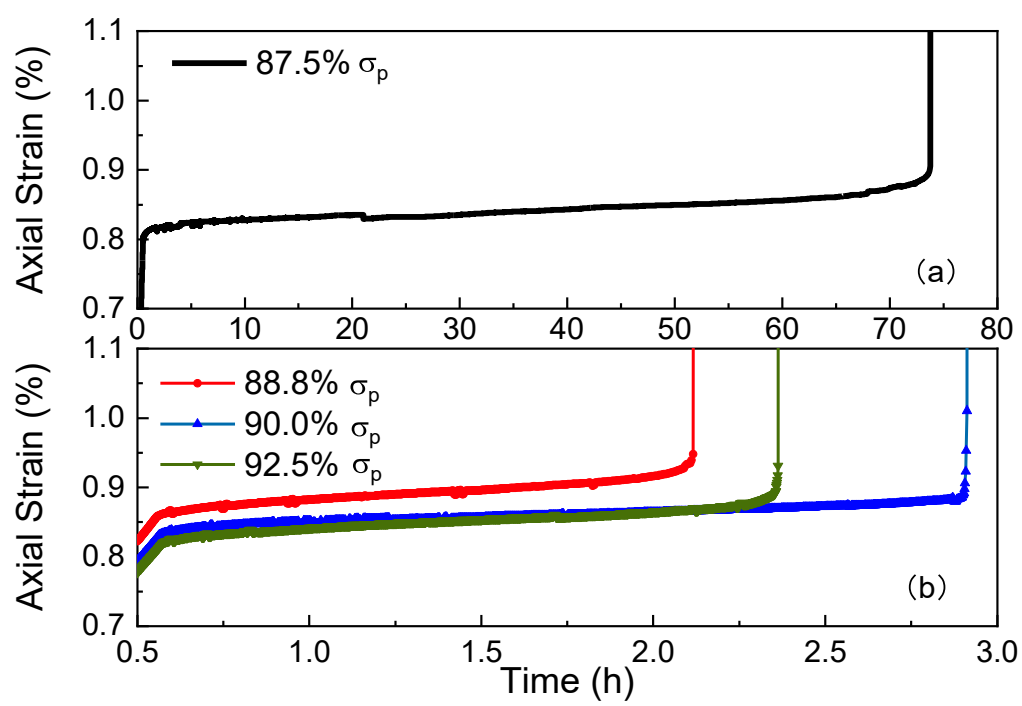

Figure 14 Uniaxial creep curves for thermally-stressed Lanhélin granite performed at different constant uniaxial stresses: (a) the creep curve for experiment $C_{-} 1$ at $87.5 \%$ of $\sigma_{p}$. (b) The creep curves for experiments

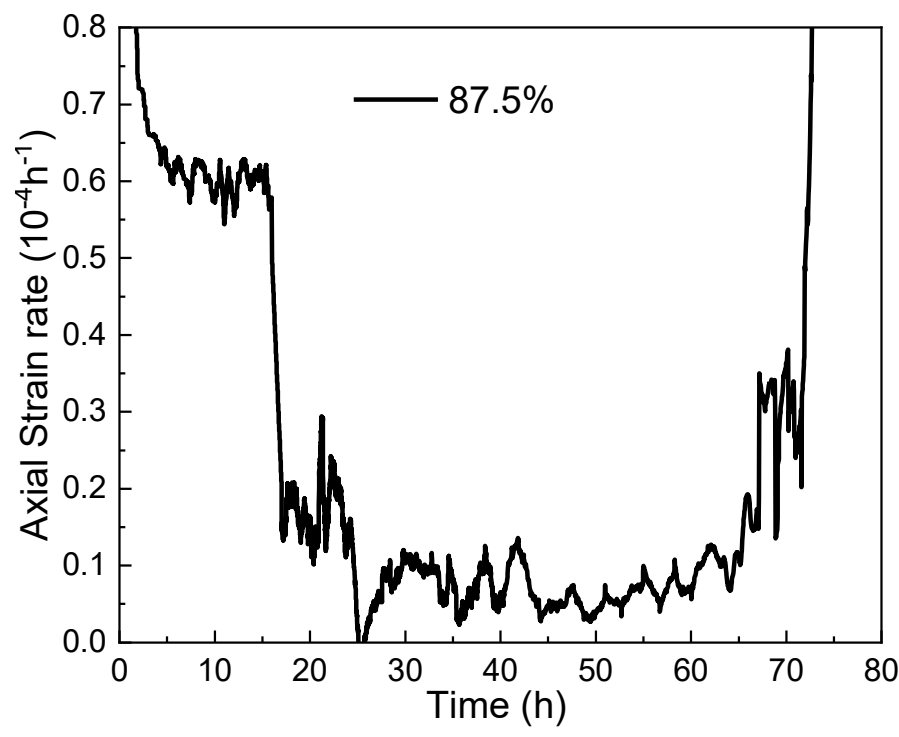




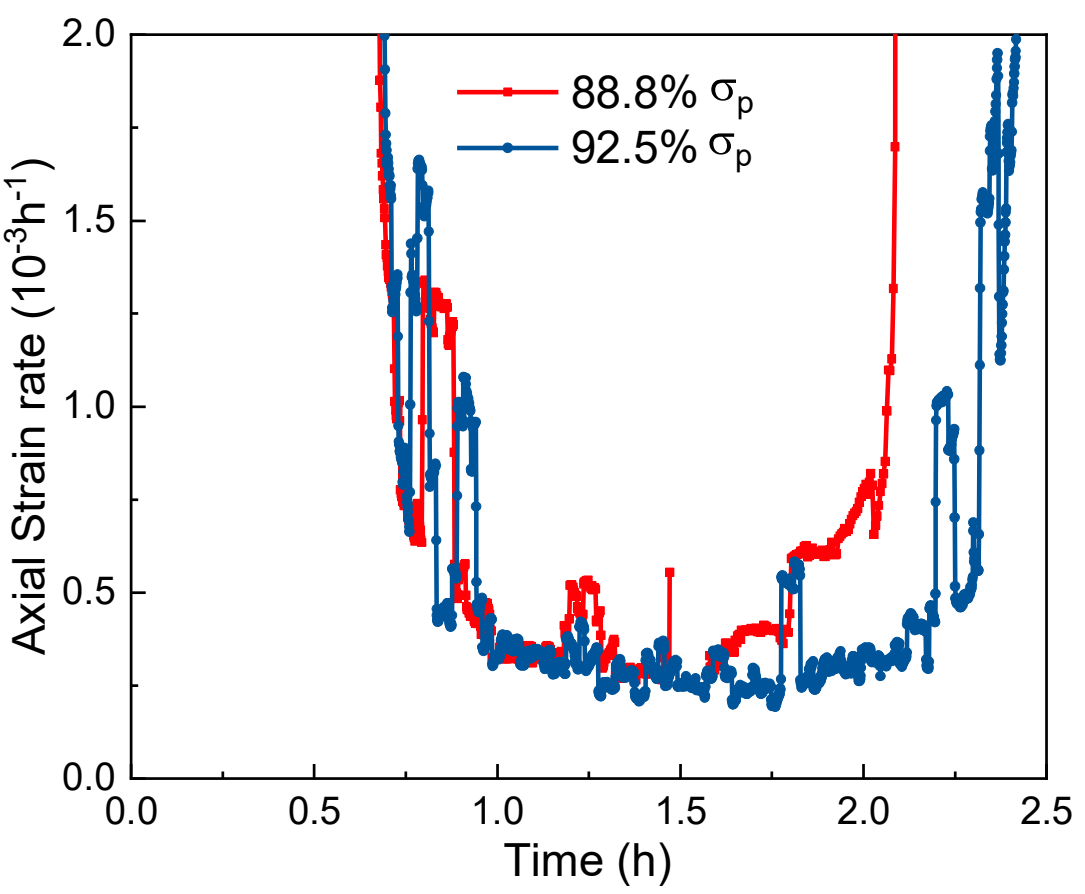

(b)

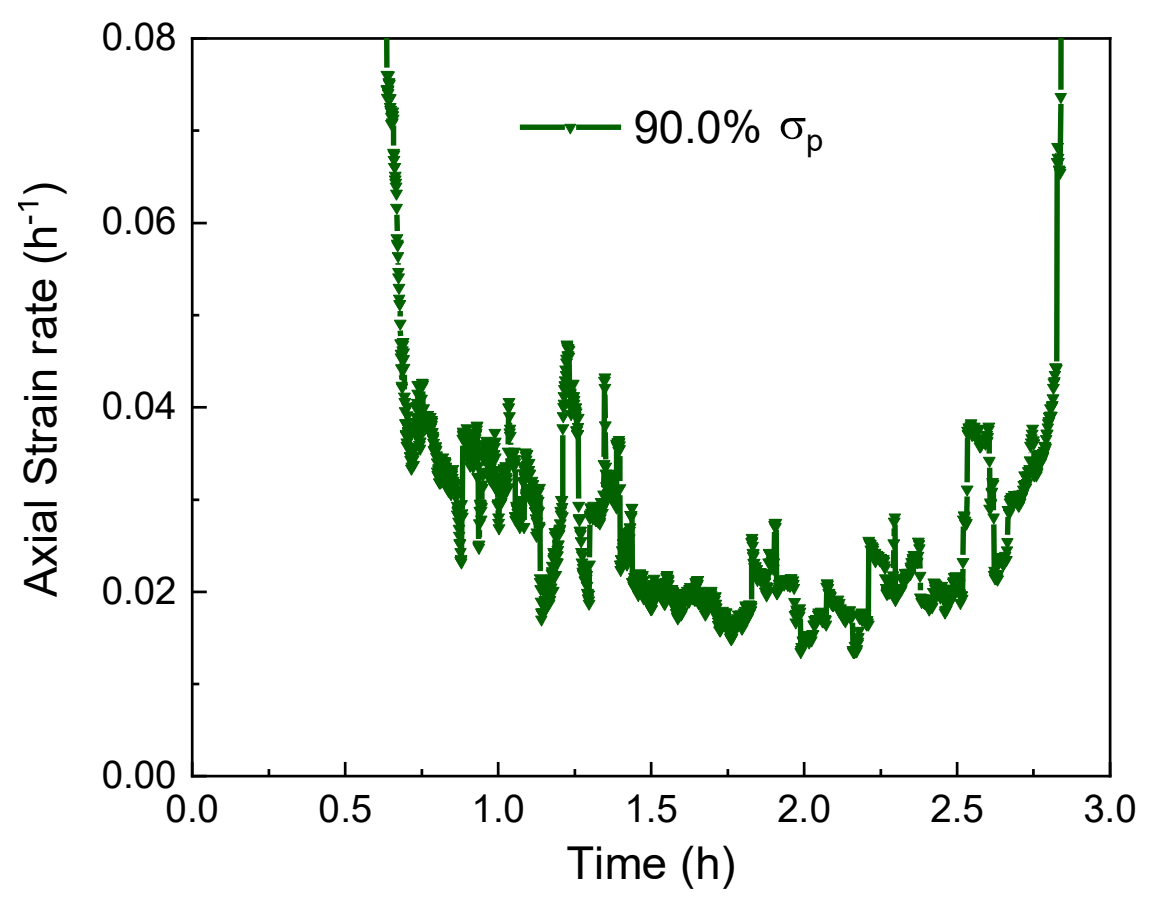

(c)

349 Figure 15 Axial strain rate as a function of time for four uniaxial creep experiments performed on thermally350 stressed Lanhélin granite (the experiments shown in Figure 14), (a) the axial strain rate curve for experiment 351 C_1, (b) the axial strain rate curves for experiments C_2 and C_4, (c) the axial strain rate curve for experiment 352 C_3 


\section{Numerical simulations}

\subsection{Multi-crack NMM model}

A pre-cracked granite specimen model of $20 \mathrm{~mm}$ in diameter and $40 \mathrm{~mm}$ in length is shown in Figure 16(a).

The real crack half-length is $4 \mathrm{~mm}$, and the crack angle $\varphi$ is $45^{\circ}$. The meshed specimen that contains multicracks is shown in Figure 16(b). The three-node triangular elements in Figure 16(b) consist of mathematical covers, and the solid black line in Figure 16(a) represents the physical boundary and discontinuities in the specimen. The thick and thin red solid lines in Figures 16(c) and (d) represent real and virtual cracks, respectively[20]. The model consists of 1108 elements, which means that this model has more than 1000 virtual cracks. Every crack in the model has two crack tips, and the SIF of every crack tip can be calculated at every simulation step. The initial virtual crack half-length is $0.042 \mathrm{~mm}$. The real crack is a part of the physical cover, and it can therefore cut an element and open and slide. There are no virtual cracks in the area of the real crack, because these elements are damaged. Virtual cracks are only present in the three-node triangular elements, and will not cut the elements. The angle and length of the virtual cracks is arbitrary, and their lengths are equal.

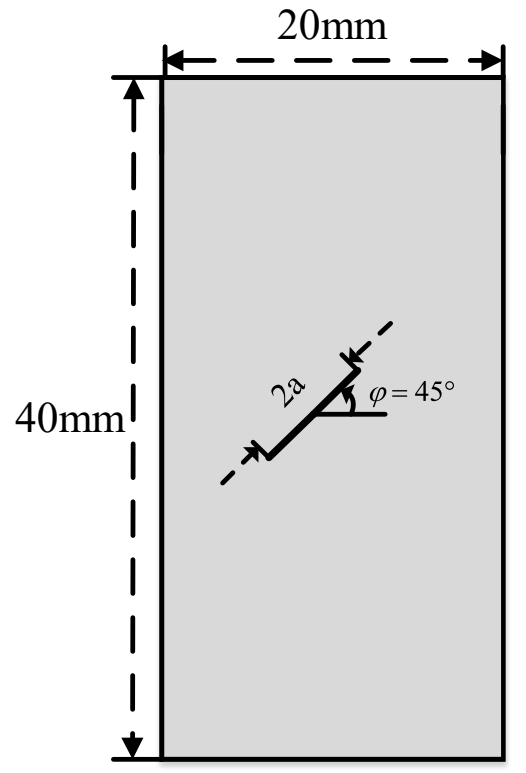

(a)

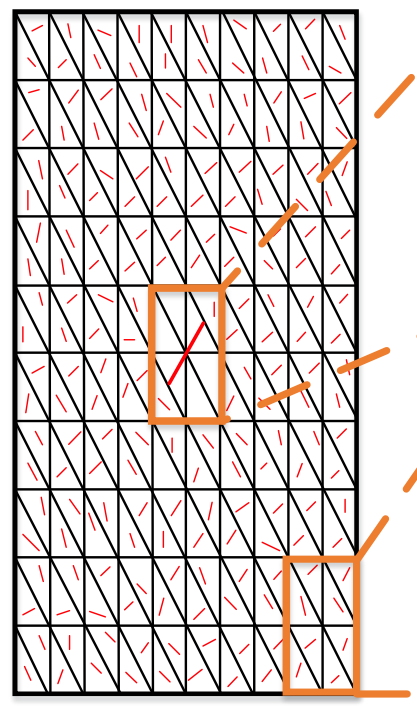

(b)

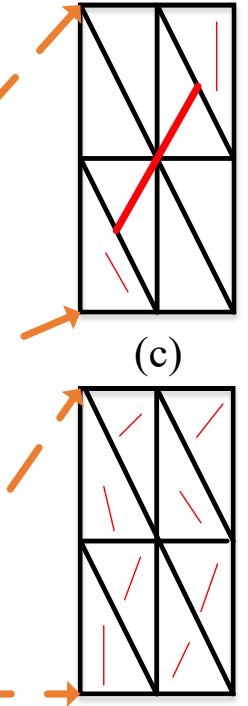

(d)

Figure $16 \mathrm{NMM}$ model of size and multi-crack distributions

When the SIFs at the crack tips are lower than the fracture toughness Kc, both the real and virtual cracks will propagate according to SCG theory. The elastic modulus of an element in which the virtual and real crack tips are located will be damaged according to Equation (12): 


$$
\left\{\begin{array}{l}
E^{\prime}=D^{*} E \\
D=\left(1-L^{\prime} / L\right)^{n} \\
L^{\prime}=V^{*} \Delta t
\end{array}\right.
$$

372 where $\mathrm{E}$ is the last step elastic modulus, $\mathrm{E}^{\prime}$ is the damaged elastic modulus, $\mathrm{D}$ is the damage factor, $\mathrm{L}$ is the 373 original crack length, $\mathrm{L}^{\prime}$ is the crack propagation length, and $\mathrm{n}$ is the damage index.

374 Because the real crack length is larger than that of a virtual crack, the SIFs of the real crack will be first equal 375 to $\mathrm{Kc}$ and then propagate according to the MCSSC. The virtual crack is very small and, because the crack length 376 at each step is very small, crack growth will occur along the original direction and will take a long time. Before 377 the virtual crack can change into a real crack, the main role of the virtual crack is to reduce the elastic modulus. 378 The virtual cracks will not cut the elements. Once the virtual crack length propagates to a pre-defined value 379 (related to model size and mesh density), it will be converted into a real crack according to the principles of 380 NMM. During crack propagation, the boundary and node of the element cannot influence the crack direction. 381 The crack can grow across the element boundary, and crack tip can be located on either the boundary, node, or 382 within the element, which results in more freedom when simulating crack propagation.

\subsection{Simulation results}

384 The improved NMM program was then used to simulate the time-dependent deformation of Lanhélin granite under constant uniaxial stress. The macroscopic mechanical properties of rock are shown in Table 2. An axial stress of $117 \mathrm{MPa}$ was applied to the numerical specimen. The bottom of specimen was fixed.

Table 2 Physico-mechanical parameters of the numerical model

\begin{tabular}{ll}
\hline Items & Value \\
Elastic modulus: $\mathrm{E}(\mathrm{GPa})$ & 21 \\
Poisson's ratio: $\mathrm{v}$ & 0.25 \\
Fracture growth constant: $\mathrm{C}$ & $1 \times 10^{-20}$ \\
Stress corrosion index: $\mathrm{n}$ & 20.3 \\
Time step: $\triangle \mathrm{t}(\mathrm{h})$ & 0.04 \\
\hline
\end{tabular}




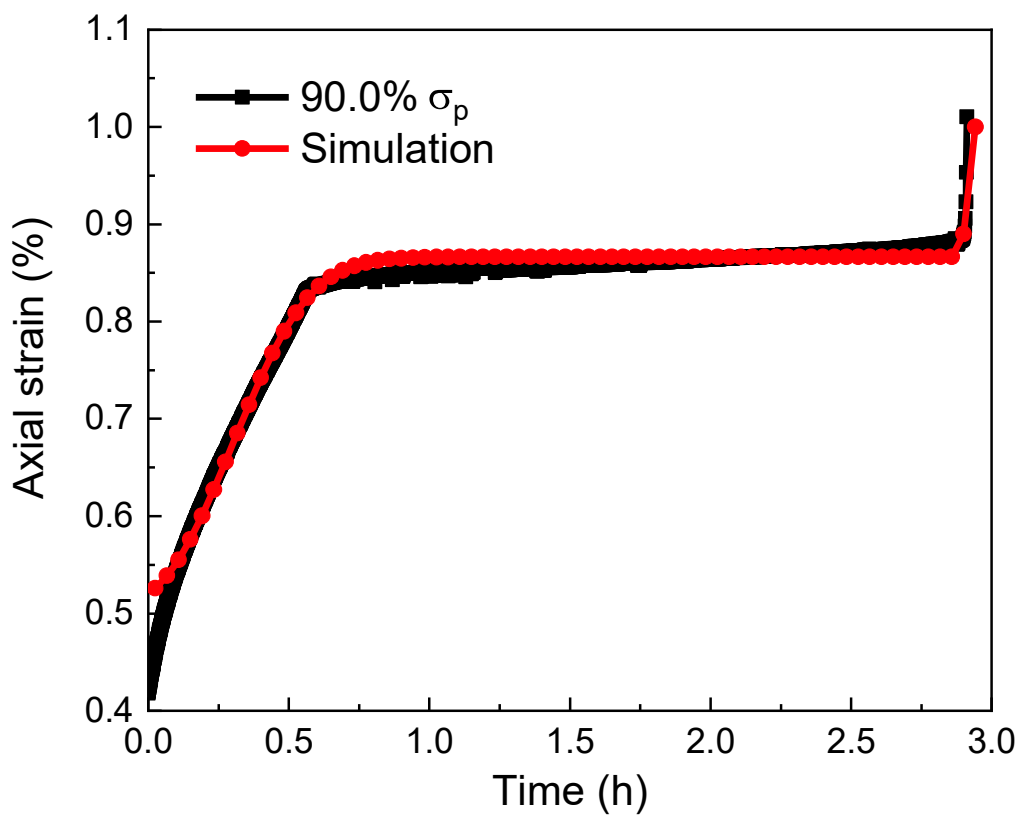

Figure 17 Comparison between experimental (black curve) and numerical (red curve) creep strain curve of

The classical creep simulation methods are the empirical method and the rheological component method, 394 which use differential equations to realize the different stages of rock creep. In this research, when the SIFs of 395 crack tips are smaller than Kc, both the virtual and real cracks propagate according to the SCG theory. During crack growth, when the crack is under the tension-shear condition, the program calculates the maximum tensile normal stress and maximum shear stress according Equation (9), when the crack is under the compress-shear condition, the program calculates the effective shear stress, after these judgements, the program then calculates the SIFs according to Equation (8), and gets the crack velocity according to Equation (7).The elastic modulus is decreased according to Equation (12) at the same time. When the SIFs are smaller than Kc, the axial strain decreases as an increasing function of time (i.e. the decelerating creep phase). When the SIFs are larger than Kc, the real crack propagates according to the MCSSC.

A comparison between experimental and numerical creep curves is shown in Figure 17. The experiment is a creep test performed on Lanhélin granite under uniaxial compression and room temperature, and the numerical model was performed under the same conditions. The experimental results clearly show the two stages of creep curve, decelerating and accelerating creep, and the numerical results are in good agreement with the experiment. In Figure 17, the initial axial strain is about $0.5 \%$. In the first $0.6 \mathrm{~h}$, the initial crack length is very small and, the 
cracks are growing at a slow rate. As a result, the strain increases slowly. From 0.6 to $2.9 \mathrm{~h}$, the axial strain

409 remains at almost a constant value. After $3 \mathrm{~h}$, the axial strain increases quickly, the cracks propagate quickly

410 and connect together to generate a macro-crack zone that, eventually, results in macroscopic sample failure.

411 Figure 18 shows the influence of virtual crack length (VL) on the time-dependent deformation of granite. As

412 shown in Figure 18, the creep strain increases with increasing VL. The larger the VL, the faster the specimen

413 goes through the decelerating creep stage and the sooner the specimen reaches the accelerating creep stage.

414 Before the simulation, the virtual crack angles in every element were fixed. During the time-dependent 415 deformation progress, the axial stress is a constant value and so the SIFs of crack tips will not increase according 416 to fracture mechanics. However, during the subcritical crack growth progress, crack tips will propagate 417 according to Eq. 7 (Charles' equation), and the crack speed and SIFs are positively correlated. The crack speed 418 and the virtual crack length (VL) are also positively correlated. We also note that increasing VL cannot change 419 the axial strain when the strain rates are constant values. The VL increase as the crack velocity increased 420 according to Equation (12), and crack velocity increase as the SIFs increased according to Equation (7). So, VL 421 and SIF are positively correlated: the longer the VL, the larger the SIF. Further, with an increase of SIF, the 422 velocity of SCG also increases. So, the propagation of micro-cracks can result in the failure of the specimen.

423 Figure 19 shows the influence of axial stress on the axial creep strain and strain rate. Five axial stress levels 424 were chosen to simulate the creep deformation, which are 116, 116.5, 117, 117.5, and $118 \mathrm{MPa}$ (in Figure 19(a)). 425 The confining pressure was set to $0 \mathrm{MPa}$ for these simulations. As the axial stress level was increased, the axial 426 strain also increased (Figure 19(a)). Figure 19(a) also shows that the time-to-failure decreased as the axial stress 427 level was increased. Figure 19(b) shows the evolution of axial strain rate as a function of time for the different 428 axial stress levels. We find that the axial strain rates are very sensitive to axial stress levels: the larger the axial 429 stress, the sooner the axial strain rate arrives at the minimum value, the sooner the sample enters the accelerating 430 creep phase, and the sooner the sample fails macroscopically (Figure 19(b)). 


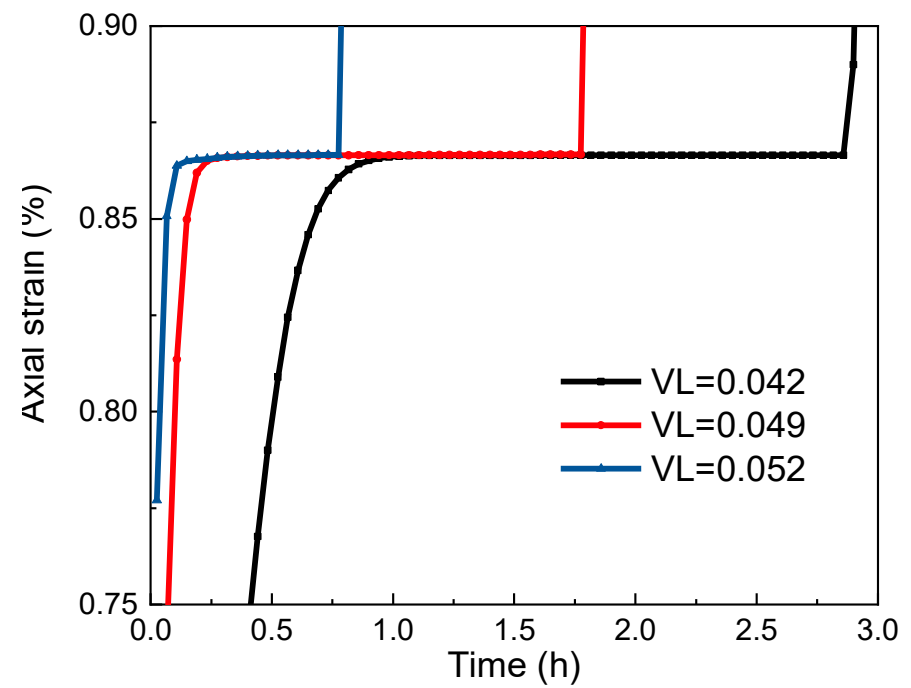

Figure 18 Influence of virtual crack length (VL) on time-dependent deformation

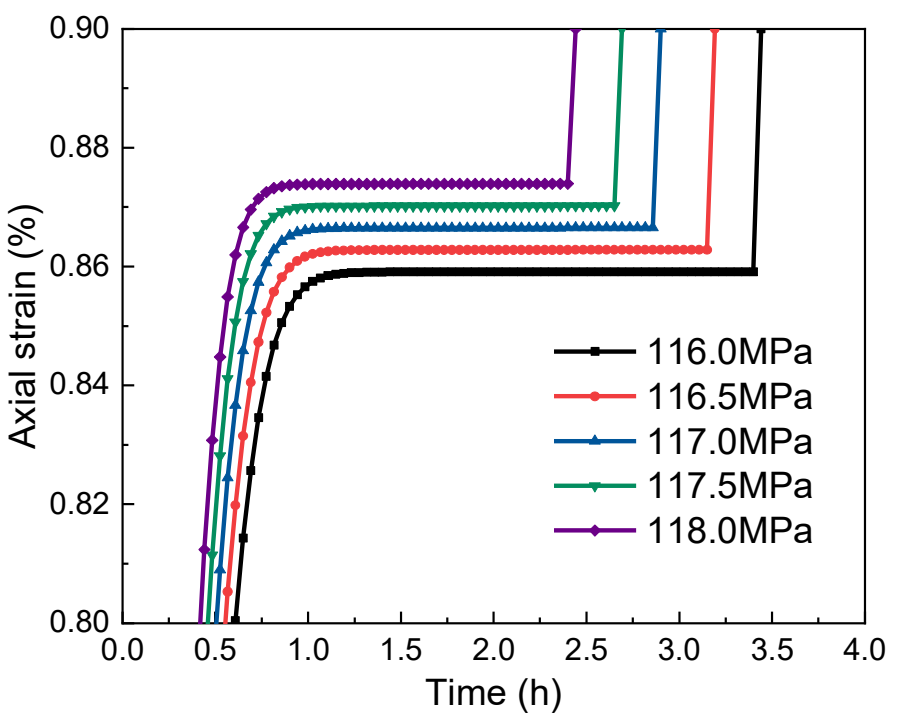

(a)

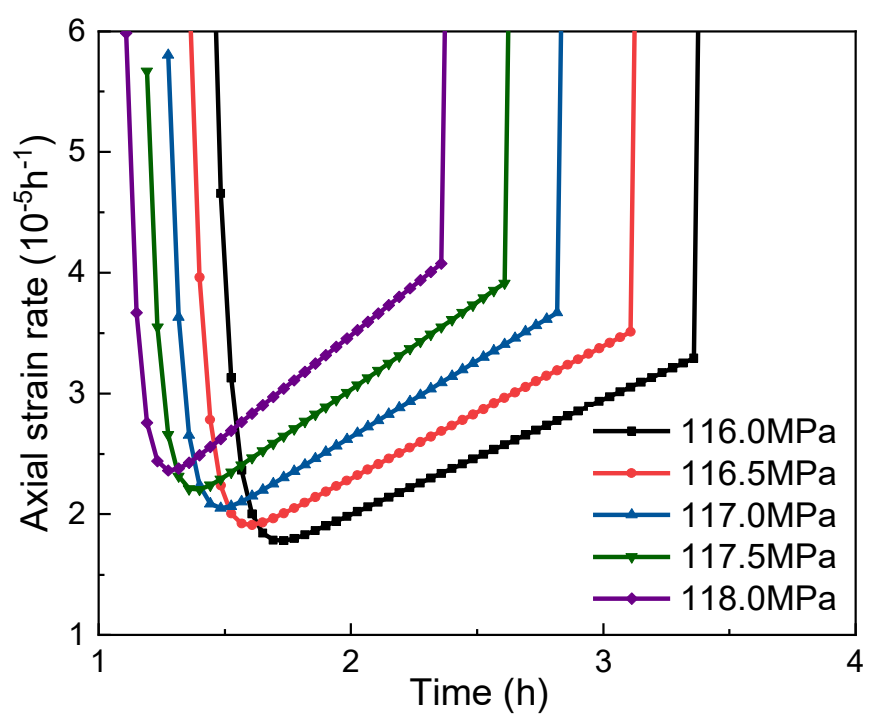


Figure 19 Influence of axial stress on time-dependent deformation. (a) Axial strain as a function of time 438 (creep curves) and (b) axial strain rate as a function of time for modeled samples at a confining pressure of 0 $\mathrm{MPa}$

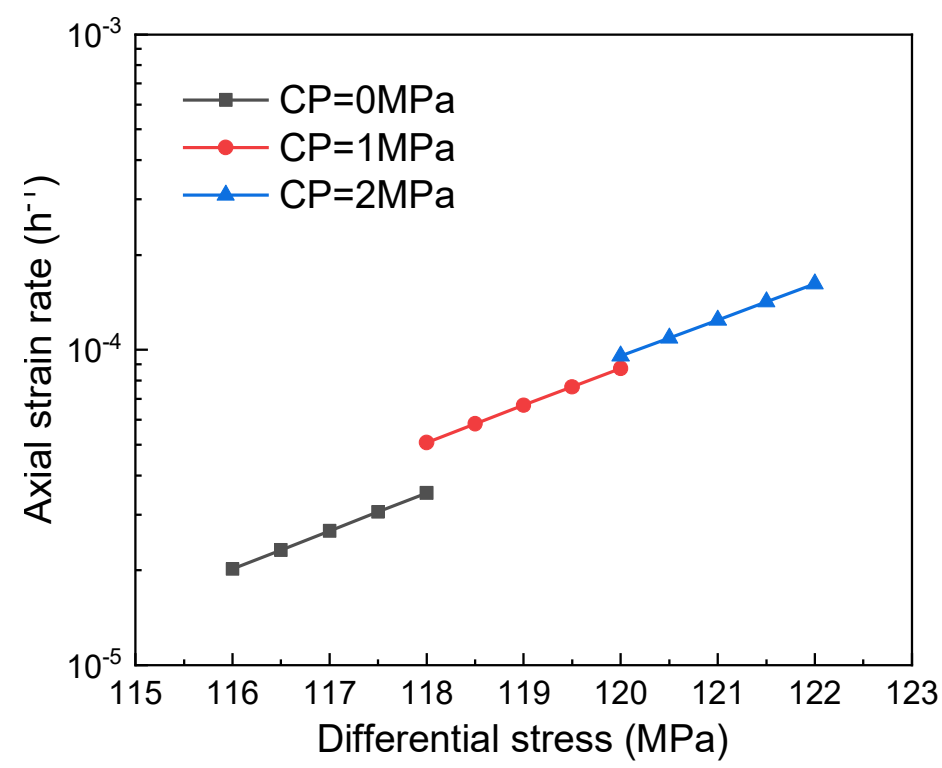

(a)

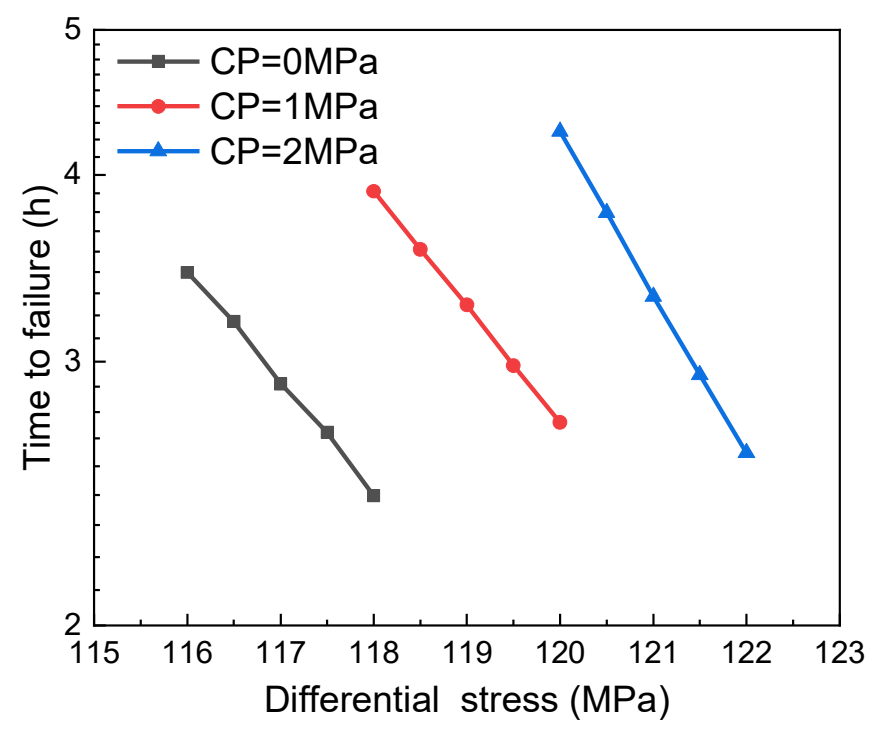

(b)

444 Figure 20 Influence of differential stress (DS) and confining pressure (CP) on time-dependent deformation.

445 (a) Axial strain rate as a function of differential stress and (b) time-to-failure as a function of differential stress 
The influence of differential stress (DS) and confining pressure (CP) on the time-to-failure and creep strain rate is illustrated in Figures 20(a) and (b), respectively. The data show that DS and CP has a profound influence on times-to-failure and creep strain rates. In Figures 20(a) and (b), when the CP is a constant value, the axial strain rate increases as a function of increasing DS: the larger the DS, the faster the axial strain rate. The timeto-failure also decreases with increasing DS. When the CP is increased, the axial strain rate and time-to-failure curves are shifted to higher values of DS. When we consider a constant value of DS (118 MPa, for example), the axial strain rates are lower for the model performed at the highest $\mathrm{CP}$, and the times-to-failure were increased. These observations are similar to the experimental results of Heap[3] and Brantut[6]. These simulation results also illustrate that a small change in differential stress and confining pressure can lead to significant changes in axial strain rate and failure time.

According to the SCG theory, when $\mathrm{K}$ is smaller than $\mathrm{Kc}$, both the virtual and real cracks will propagate at a very low velocity. It is therefore not easy to observe the crack propagation process. On the other hand, if $\mathrm{K}$ is larger than Kc, the real crack will propagate according to the MCSSC. According to Bobet[58, 59], since the stresses adjacent to the flaw tip are much higher than the strength of the material, the crack tip will likely propagate. In other zones of the material, it is not as easy to initiate cracking. Stress concentration effects at the crack tips can also inhibit the initiation of surrounding cracks. The area where crack initiation is most likely is the area containing the crack initial tip and crack boundary. Figure 21 shows the real crack propagation path under a constant stress. Figures 21(a), (d), (g), and (j) show the initial real crack propagation, crack initiation, and coalescence. As SCG progresses, the real crack propagates according to the MCSSC, because $\sigma_{1}$ is larger than $\sigma_{3}$. As a result, the crack extends in the direction of $\sigma_{1}$. Because of NMM theory, the crack can propagate by cutting through the elements, which is different from FEM and DEM in which the crack can only propagate along the boundary of the elements. Crack tips in this simulation are not restricted to the node or boundary, but can also exist within the element. After the crack propagates, the crack face is opened too. The program can calculate the contact state at every node of the crack by adding and subtracting the spring to make sure the crack 472 surface is not embedded according to contact theory. Figures 21(b), (c), (e), (f), (h), (i), (k), and (l) show the 473 displacement of the specimen in the $\mathrm{X}$ - and $\mathrm{Y}$-direction under a constant stress. At the beginning of simulation, 474 the X-direction displacement is symmetric from left to right, and the Y-direction displacement is symmetric 
475 from top to bottom. The crack propagation can greatly influence the displacement and facilitate macroscopic

476 failure. The maximum displacement moves gradually toward the crack during crack propagation. Figure 22

477 shows a comparison between the failure mode of a specimen with a $45^{\circ}$ crack from one of the NMM numerical

478 simulations and a sample deformed under a constant uniaxial stress in the laboratory (the experiment was

479 performed by Qin[60]). Figure 22 shows that the failure mode observed during the NMM simulation is very

480 similar to that observed in the laboratory.

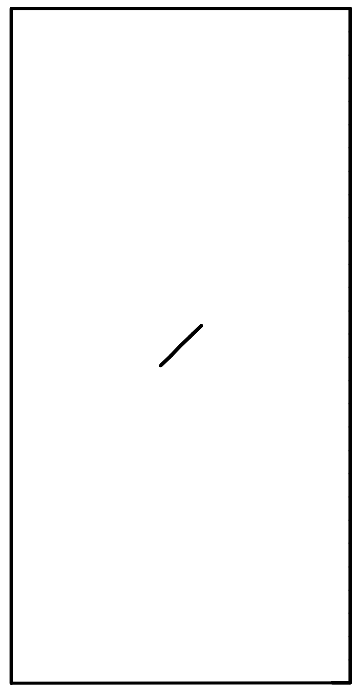

(a)

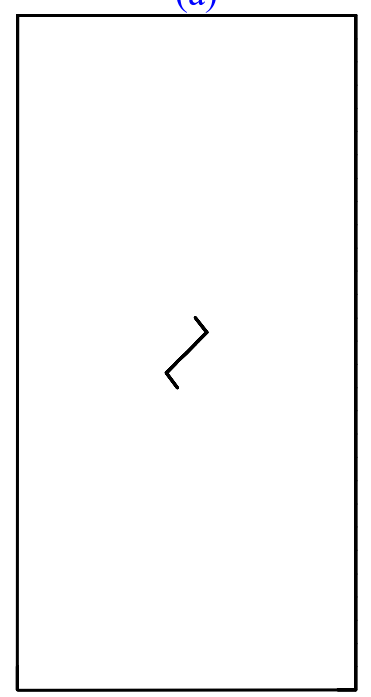

(d)

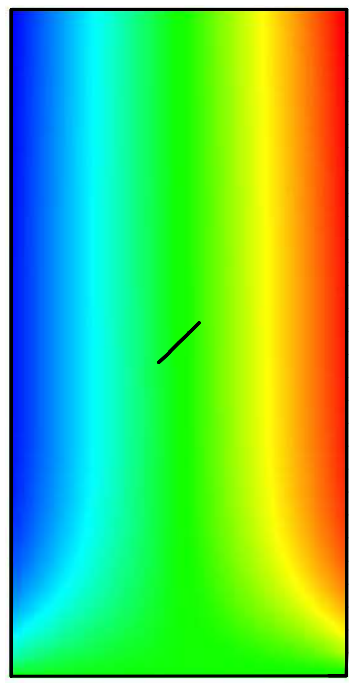

(b)

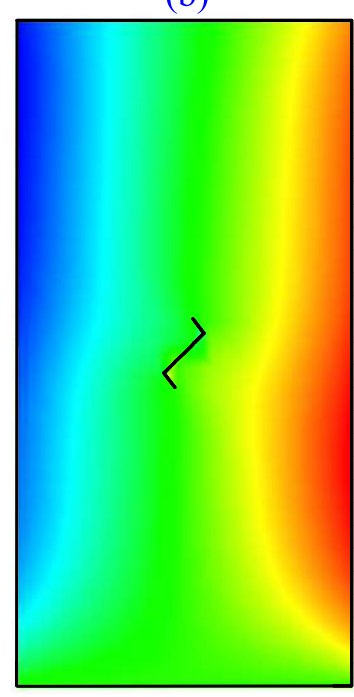

(e)
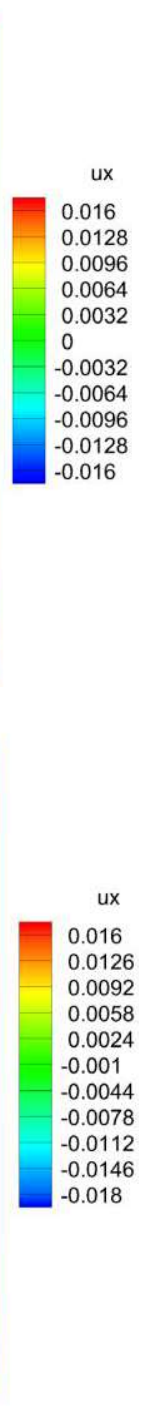

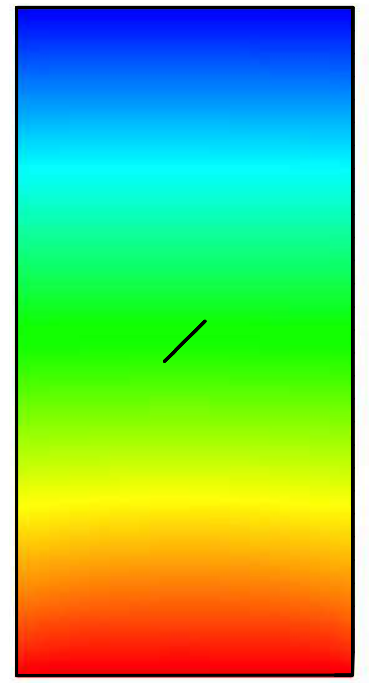

(c)

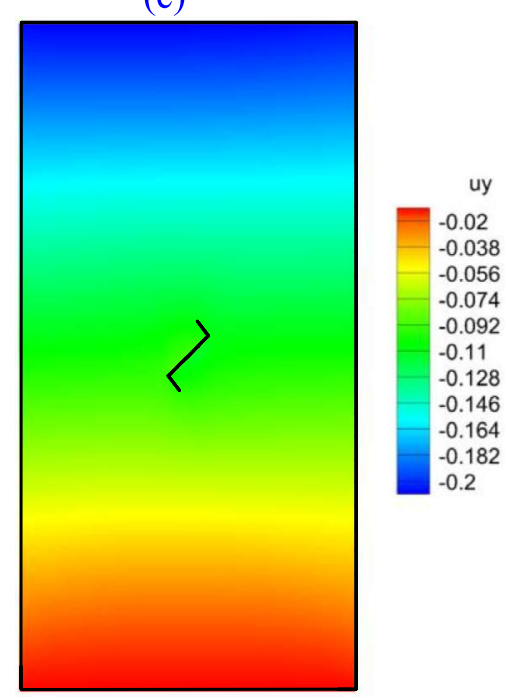

(f) 


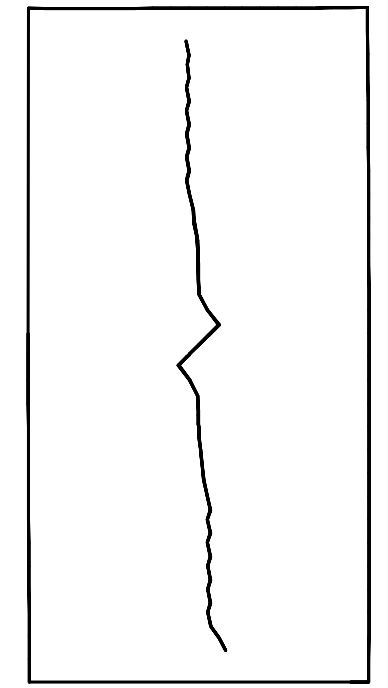

(g)

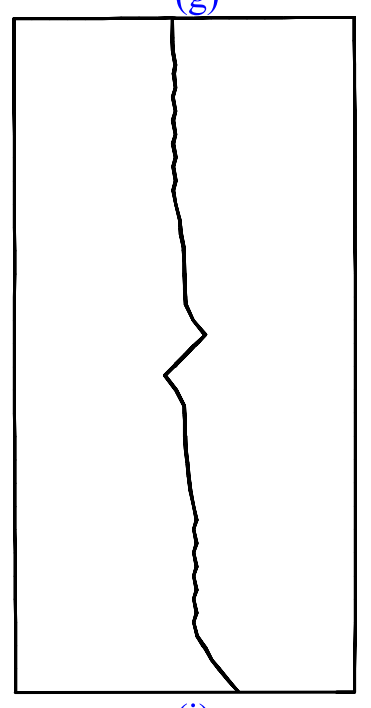

(j)

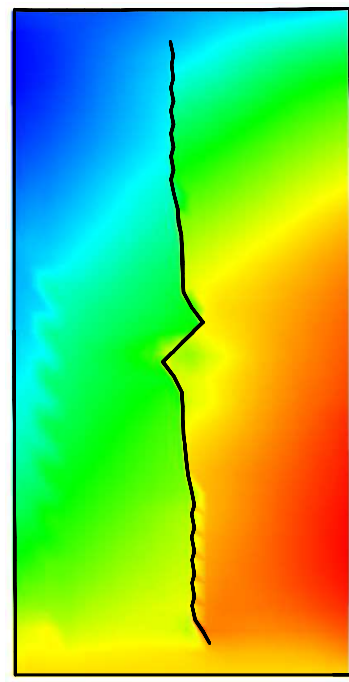

(h)

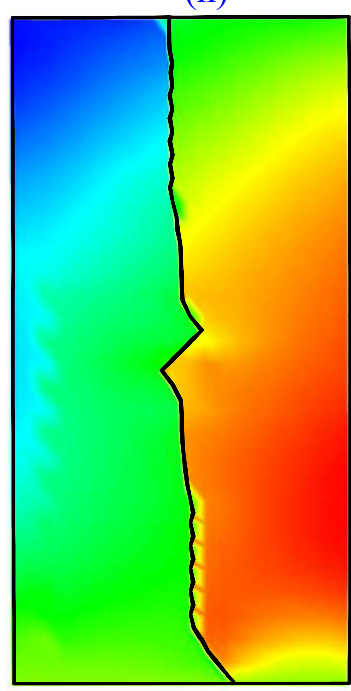

(k)

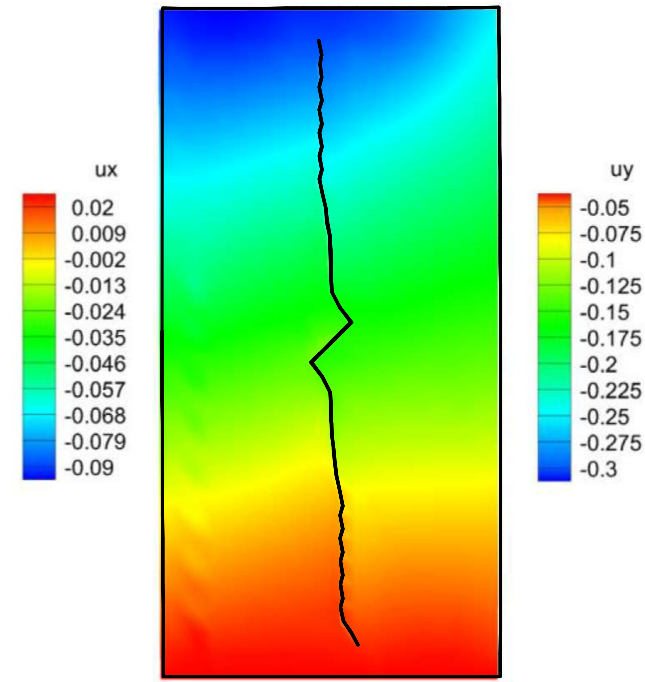

(i)

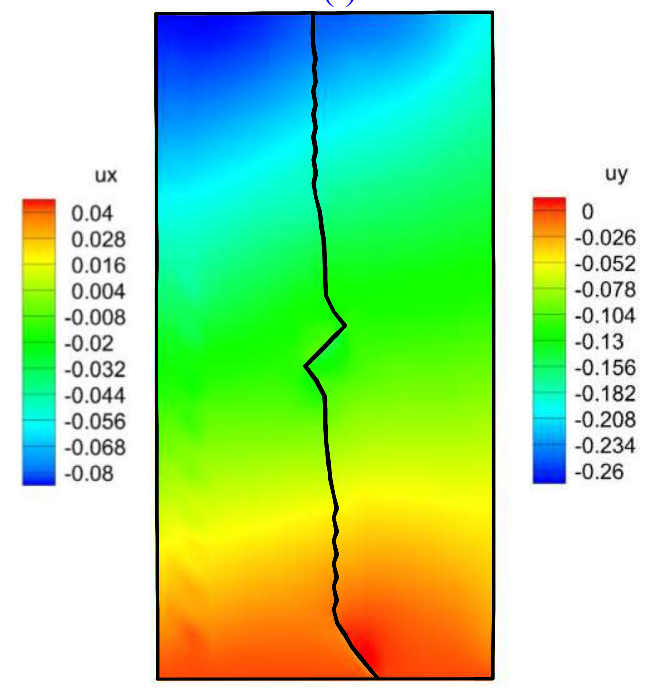

(1)

Figure 21 Crack propagation path and displacement in the $\mathrm{X}$ - and $\mathrm{Y}$-direction under time-dependent deformation when $\mathrm{K}$ is larger than $\mathrm{Kc}$
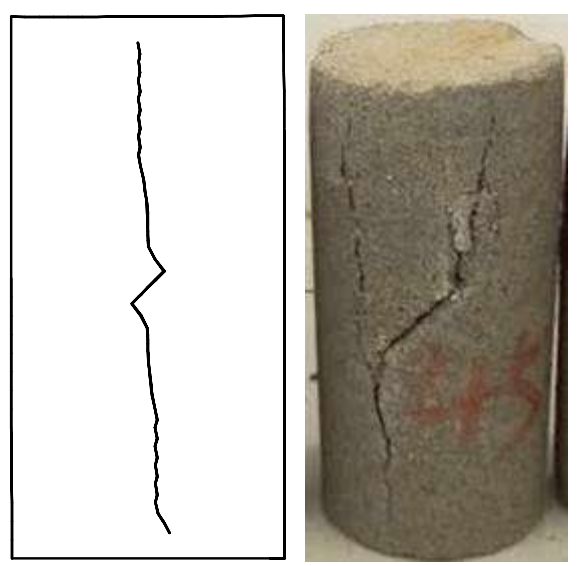

Figure 22 Comparison between the failure mode of a specimen with a $45^{\circ}$ crack from one of the NMM numerical simulations and a sample deformed under a constant uniaxial stress in the laboratory (the experiment was performed by Qin[60]) 


\section{Concluding remarks}

In the present paper, the time-dependent deformation of granite is modeled by combining SCG and NMM on the MATLAB ${ }^{\circledR}$ platform. This combined method replaces the traditional creep component model method. In the model, we introduced virtual cracks into the NMM to realize crack initiation. Before the virtual crack can change into a real cack, the virtual crack must be located at every element of the NMM, propagate in a line, and reduce the elastic modulus of the elements. No opening or sliding occurs during virtual crack propagation: only real cracks can open and slide. Because crack coalescence is very complicated during crack propagation, we introduce three coalescence models to deal with this problem, which are the "tip and tip", "tip and boundary", and "boundary and boundary" crack models. In order to reflect the influence of crack propagation on the creep deformation of Lanhélin granite, we use Charles' equation to calculate the crack velocity. When stress intensity factor $\mathrm{K}$ is smaller than the fracture toughness $\mathrm{Kc}$, the crack growth length is linked to the local damage (using an exponential material softening law) to reduce the strength of the granite. When $\mathrm{K}$ is larger than $\mathrm{Kc}$, the cracks propagate according to the MCSSC. Parameter sensitivity analysis for the improved NMM program was performed and validated against experimental data. The influence of crack length, confining pressure, and differential stress were then investigated. The results show that the microstructure of granite has a great influence on time-dependent deformation. We found that the virtual crack length (VL), differential stress (DS), and confining pressure (CP) all play a major role in governing elastic deformation. With an increase of VL, the specimen can reach the accelerating creep stage quickly, because the VL can greatly influence the SIF at the

515 decreases the creep strain rate and increases time-to-failure at a constant stress. Even a small change of DS can 516 significantly increase and decrease the creep strain rate and time-to-failure, respectively. In addition, we find 517 that the cracks propagate along the direction of the maximum principle stress. When the SIF of the crack tip is 518 larger than $\mathrm{Kc}$, the real cracks start to initiate and propagate. The crack can also influence the specimen 519 displacement greatly during propagation. The maximum displacement also moves towards the crack during crack propagation, which means that the crack zones are more likely to be broken. The results of the numerical simulations are in good agreement with the experimental results and therefore show that the improved NMM program is suitable for modeling the time-dependent creep deformation of rocks. Last but not least, the improved NMM program also simulates large displacements during creep deformation. The cracks in the specimen can 
open and slide without the influence of the element node or boundary, therefore reducing the reliance on the

525 grid, which makes it possible for the program to more accurately simulate crack propagation during creep 526 deformation.

\section{Acknowledgments}

The work was jointly supported by NSFC $(51974062,41672301,51950410595,51761135102)$, National Key Research and Development Program of China (2017YFC1503100), Fundamental Research Funds for the Central Universities of China (N180101028) and the financial support from the China Scholarship Council (File No. 201906080054). The authors also thank Bertrand Renaudié, Luke Griffiths, and Lucille Carbillet. The comments of two reviewers helped improve this paper.

\section{References}

[1] Dawson PR, Munson DE. Numerical simulation of creep deformations around a room in a deep potash mine. International Journal of Rock Mechanics \& Mining Sciences \& Geomechanics Abstracts. $1983 ; 20(1): 33-42$.

[2] Tsai LS, Hsieh YM, Weng MC, Huang TH, Jeng FS. Time-dependent deformation behaviors of weak sandstones. International Journal of Rock Mechanics and Mining Sciences. 2008;45(2):144-54.

[3] Heap MJ, Baud P, Meredith PG, Bell AF, Main IG. Time - dependent brittle creep in Darley Dale sandstone. Journal of Geophysical Research Atmospheres. 2009;114(B7).

[4] Scholz CH. Mechanism of creep in brittle rock. Journal of Geophysical Research. 1968;73(10):3295-302.

[5] Griggs D. Creep of rocks. The Journal of Geology. 1939;47(3):225-51.

[6] Brantut N, Heap MJ, Meredith PG, Baud P. Time-dependent cracking and brittle creep in crustal rocks: A review. Journal of Structural Geology. 2013;52(5):17-43.

[7] Heap MJ, Baud P, Meredith PG. Influence of temperature on brittle creep in sandstones. Geophysical Research Letters. 2009;36(19):308-.

[8] Mongi K. Study of the elastic shocks caused by the fracture of heterogeneous materials and its relation to earthquakes phenomena. Bulletin of the Earthquake Research Institute. 1962;40(125-73.

[9] Charles RJ. Static Fatigue of Glass. I. Journal of Applied Physics. 1958;29(11):1549-53. 
550 [10] Meredith P, Atkinson B. Stress corrosion and acoustic emission during tensile crack propagation in Whin 551 Sill dolerite and other basic rocks. Geophysical Journal International. 1983;75(1):1-21.

552 [11] Evans AG. A method for evaluating the time-dependent failure characteristics of brittle materials — and 553 its application to polycrystalline alumina. Journal of Materials Science. 1972;7(10):1137-46.

554 [12] Olson JE. Joint pattern development: Effects of subcritical crack growth and mechanical crack 555 interaction. Journal of Geophysical Research: Solid Earth. 1993;98(B7):12251-65.

556 [13] Nara Y, Kaneko K. Study of subcritical crack growth in andesite using the Double Torsion test. 557 International Journal of Rock Mechanics \& Mining Sciences. 2005;42(4):521-30.

558 [14] Kies J, Clarck A. Fracture propagation rates and times to fail following proof stress in bulk glass. ICF2, 559 Brighton. UK1969.

560 [15] Nara Y, Morimoto K, Yoneda T, Hiroyoshi N, Kaneko K. Effects of humidity and temperature on 561 subcritical crack growth in sandstone. International Journal of Solids and Structures. 2011;48(7-8):1130-40. 562 [16] Nara Y, Takada M, Mori D, Owada H, Yoneda T, Kaneko K. Subcritical crack growth and long-term 563 strength in rock and cementitious material. International Journal of Fracture. 2010;164(1):57-71.

564 [17] Gioda G. A finite element solution of non-linear creep problems in rocks. International Journal of Rock 565 Mechanics \& Mining Sciences \& Geomechanics Abstracts. 1981;18(1):35-46.

566 [18] Desai CS, Sane S, Jenson J. Constitutive Modeling Including Creep- and Rate-Dependent Behavior and 567 Testing of Glacial Tills for Prediction of Motion of Glaciers. International Journal of Geomechanics. $568 \quad 2011 ; 11(6): 465-76$.

569 [19] Brantut N, Baud P, Heap MJ, Meredith PG. Micromechanics of brittle creep in rocks. Journal of $570 \quad$ Geophysical Research Solid Earth. 2012;117(B8):1133-72.

571 [20] Li X, Konietzky H. Numerical simulation schemes for time-dependent crack growth in hard brittle rock. 572 Acta Geotechnica. 2015;10(4):513-31.

573 [21] Shi GH. Discontinuous Deformation Analysis A New Numerical Model for the Static and Dynamics of 574 Block Systems 1989.

575 [22] Gao Y, Gao F, Ronald YM. Rock creep modeling based on discontinuous deformation analysis. 576 International Journal of Mining Science and Technology. 2013;23(5):757-61. 
[23] Zheng H, Zhang P, Du X. Dual form of discontinuous deformation analysis. Computer Methods in 578 Applied Mechanics \& Engineering. 2016;305(196-216.

579 [24] Xu T, Zhou GL, Heap MJ, Zhu WC, Chen CF, Baud P. The Influence of Temperature on Time580 Dependent Deformation and Failure in Granite: A Mesoscale Modeling Approach. Rock Mechanics and Rock 581 Engineering. 2017;50(9):2345-64.

582 [25] Xu T, Xu Q, Tang CA, Ranjith PG. The evolution of rock failure with discontinuities due to shear creep. 583 Acta Geotechnica. 2013;8(6):567-81.

584 [26] Shi G-H. Manifold method of material analysis. Army Research Office Research Triangle Park NC, 585 1991. p. 51 76.

586 [27] Shi GH. Modeling rock joint and bocks by Manifold method. Procus Symporock Mech. 1992.

587 [28] Ning YJ, An XM, Ma GW. Footwall slope stability analysis with the numerical manifold method. 588 International Journal of Rock Mechanics and Mining Sciences. 2011;48(6):964-75.

589 [29] An XM, Ning YJ, Ma GW, He L. Modeling progressive failures in rock slopes with non - persistent 590 joints using the numerical manifold method. International Journal for Numerical \& Analytical Methods in 591 Geomechanics. 2014;38(7):679 - 701.

592 [30] Zheng H, Liu F, Du X. Complementarity problem arising from static growth of multiple cracks and 593 MLS-based numerical manifold method. Computer Methods in Applied Mechanics \& Engineering. $594 \quad 2015 ; 295(150-71$.

595 [31] Yang Y, Xu D, Liu F, Zheng H. Modeling the entire progressive failure process of rock slopes using a 596 597 598 599 2011;38(1):40-9.

600 [33] An XM, Ma GW, Cai YC, Zhu HH. A new way to treat material discontinuities in the numerical 601 manifold method. Computer Methods in Applied Mechanics \& Engineering. 2011;200(47-48):3296-308. 602 603 [34] Wu W, Yang Y, Zheng H. Enriched mixed numerical manifold formulation with continuous nodal gradients for dynamics of fractured poroelasticity. Applied Mathematical Modelling. 2020;86(225-58. 
604 [35] Yang Y, Tang X, Zheng H, Liu Q, Liu Z. Hydraulic fracturing modeling using the enriched numerical 605 manifold method. Applied Mathematical Modelling. 2017.

606 [36] Zhou G-l, Xu T, Zhu W-c, Konietzky H, Heng Z, Yu X. A damage-based numerical manifold approach 607 to crack propagation in rocks. Engineering Analysis with Boundary Elements. 2020;117(76-88.

608 [37] Zheng H, Liu F, Li C. Primal mixed solution to unconfined seepage flow in porous media with numerical 609 manifold method. Applied Mathematical Modelling. 2015;39(2):794-808.

610 [38] Yang Y, Zheng H, Sivaselvan MV. A rigorous and unified mass lumping scheme for higher-order 611 elements. Computer Methods in Applied Mechanics \& Engineering. 2017;319(491-514.

612 [39] Yu XY, Xu T, Heap M, Zhou GL, Baud P. Numerical Approach to Creep of Rock Based on the 613 Numerical Manifold Method. International Journal of Geomechanics. 2018;18(11):04018153.

614 [40] Liu J, Chen Q. A numerical manifold method for simulating creep of rocks. Rock and Soil Mechanics. $615 \quad 2012 ; 33(4): 1203-9$.

616 [41] He J, Liu QS, Wu ZJ. Creep crack analysis of viscoelastic material by numerical manifold method. 617 Engineering Analysis with Boundary Elements. 2017;80(72-86.

618 [42] Erdogan F, Sih GC. On the Crack Extension in Plates Under Plane Loading and Transverse Shear. 619 Journal of Basic Engineering. 1963;85(4):519-25.

620 [43] Wu Z, Wong LNY. Frictional crack initiation and propagation analysis using the numerical manifold 621 method. Comput Geotech. 2012;39(1):38-53.

622 [44] Brady BHG, Brown ET. Rock Mechanics for underground mining1993.

623 [45] Atkinson BK. Subcritical crack growth in geological materials. Journal of Geophysical Research Solid 624 Earth. 1984;89(B6):4077-114.

625 [46] Nara Y, Harui T, Kashiwaya K. Influence of calcium ions on subcritical crack growth in granite. 626 International Journal of Rock Mechanics \& Mining Sciences. 2018;102(71-7. 627 [47] Liu X-w, Liu Q-s, He J, Liu B. Modified contact model with rock joint constitutive in numerical 628 manifold method. Engineering Analysis with Boundary Elements. 2018;93(63-71.

629 [48] Shi GH. Discontinuous deformation analysis: a new numerical model for the statics and dynamics of 630 deformable block structures. Engineering Computations. 1992;9(2):157-68. 
631 [49] Siratovich PA, Villeneuve MC, Cole JW, Kennedy BM, Bégué F. Saturated heating and quenching of

632 three crustal rocks and implications for thermal stimulation of permeability in geothermal reservoirs.

633 International Journal of Rock Mechanics and Mining Sciences. 2015;80(265-80.

634 [50] Wadsworth FB, Heap MJ, Damby DE, Hess K-U, Najorka J, Vasseur J, et al. Local geology controlled 635 the feasibility of vitrifying Iron Age buildings. Scientific Reports. 2017;7(1):40028.

636 [51] Jing L, Nordlund E, Stephansson O. An experimental study on the anisotropy and stress-dependency of the strength and deformability of rock joints. International Journal of Rock Mechanics and Mining Sciences \& 638 Geomechanics Abstracts. 1992;29(6):535-42.

639 [52] Boulon MJ, Selvadurai APS, Benjelloun H, Feuga B. Influence of rock joint degradation on hydraulic 640 conductivity. International Journal of Rock Mechanics and Mining Sciences \& Geomechanics Abstracts. $641 \quad 1993 ; 30(7): 1311-7$

642 [53] Homand F, Belem T, Souley M. Friction and degradation of rock joint surfaces under shear loads. International Journal for Numerical Analytical Methods in Geomechanics. 2001;25(10):973-99.

644 [54] Chandler MR, Meredith PG, Brantut N, Crawford BR. Effect of temperature on the fracture toughness of 645 anisotropic shale and other rocks. Geological Society. 2017;454(1):295-303.

646 [55] Griffiths L, Heap MJ, Baud P, Schmittbuhl J. Quantification of microcrack characteristics and 647 implications for stiffness and strength of granite. International Journal of Rock Mechanics and Mining $648 \quad$ Sciences. 2017;100(138-50.

649 [56] Brace W, Paulding Jr B, Scholz C. Dilatancy in the fracture of crystalline rocks. Journal of Geophysical 650 Research. 1966;71(16):3939-53.

651 [57] Eberhardt E, Stead D, Stimpson B. Quantifying progressive pre-peak brittle fracture damage in rock 652 during uniaxial compression. International Journal of Rock Mechanics and Mining Sciences. 1999;36(3):36165380.

654 [58] Bobet A, Einstein HH. Numerical modeling of fracture coalescence in a model rock material. 655 International Journal of Fracture. 1998;92(3):221-52.

656 [59] Bobet A, Einstein HH. Fracture coalescence in rock-type materials under uniaxial and biaxial 657 compression. International Journal of Rock Mechanics and Mining Sciences. 1998;35(7):863-88. 
658 [60] Nan Q, Jinlong Z, Yongyan W. Uniaxial compressive strength and creep rate of single crack rock with 659 different angles. CHINESE JOURNAL OF APPLIED MECHANICS. 2018;35(03):662-7+97. 660 